\title{
Characterisation of boundary layer turbulent processes by the Raman lidar BASIL in the frame of $\mathrm{HD}(\mathrm{CP})^{2}$ Observational Prototype Experiment
}

\author{
Paolo Di Girolamo $^{1}$, Marco Cacciani ${ }^{2}$, Donato Summa ${ }^{1}$, Andrea Scoccione ${ }^{2}$, Benedetto De Rosa ${ }^{1}$, Andreas Behrendt ${ }^{3}$, \\ and Volker Wulfmeyer ${ }^{3}$ \\ ${ }^{1}$ Scuola di Ingegneria, Università degli Studi della Basilicata, Viale dell'Ateneo Lucano n. 10, 85100 Potenza, Italy \\ ${ }^{2}$ Dipartimento di Fisica, Università di Roma "La Sapienza", Piazzale Aldo Moro, n. 2, 00100 Rome, Italy \\ ${ }^{3}$ Institut für Physik und Meteorologie, Universität Hohenheim, Garbenstraße 30, D-70599 Stuttgart, Germany
}

Correspondence to: Paolo Di Girolamo (digirolamo@unibas.it)

Received: 30 June 2016 - Published in Atmos. Chem. Phys. Discuss.: 7 July 2016

Revised: 27 October 2016 - Accepted: 7 November 2016 - Published: 17 January 2017

\begin{abstract}
Measurements carried out by the University of Basilicata Raman lidar system (BASIL) are reported to demonstrate the capability of this instrument to characterise turbulent processes within the convective boundary layer (CBL). In order to resolve the vertical profiles of turbulent variables, high-resolution water vapour and temperature measurements, with a temporal resolution of $10 \mathrm{~s}$ and vertical resolutions of 90 and $30 \mathrm{~m}$, respectively, are considered. Measurements of higher-order moments of the turbulent fluctuations of water vapour mixing ratio and temperature are obtained based on the application of autocovariance analyses to the water vapour mixing ratio and temperature time series. The algorithms are applied to a case study (11:3013:30 UTC, 20 April 2013) from the High Definition Clouds and Precipitation for Climate Prediction $\left(\mathrm{HD}(\mathrm{CP})^{2}\right)$ Observational Prototype Experiment (HOPE), held in western Germany in the spring 2013. A new correction scheme for the removal of the elastic signal crosstalk into the low quantum number rotational Raman signal is applied. The noise errors are small enough to derive up to fourth-order moments for both water vapour mixing ratio and temperature fluctuations.

To the best of our knowledge, BASIL is the first Raman lidar with a demonstrated capability to simultaneously retrieve daytime profiles of water vapour turbulent fluctuations up to the fourth order throughout the atmospheric CBL. This is combined with the capability of measuring daytime profiles of temperature fluctuations up to the fourth order. These measurements, in combination with measurements from other li-
\end{abstract}

dar and in situ systems, are important for verifying and possibly improving turbulence and convection parameterisation in weather and climate models at different scales down to the grey zone (grid increment $\sim 1 \mathrm{~km}$; Wulfmeyer et al., 2016).

For the considered case study, which represents a wellmixed and quasi-stationary CBL, the mean boundary layer height is found to be $1290 \pm 75 \mathrm{~m}$ above ground level (a.g.l.). Values of the integral scale for water vapour and temperature fluctuations at the top of the CBL are in the range of 70-125 and 75-225 s, respectively; these values are much larger than the temporal resolution of the measurements $(10 \mathrm{~s})$, which testifies that the temporal resolution considered for the measurements is sufficiently high to resolve turbulent processes down to the inertial subrange and, consequently, to resolve the major part of the turbulent fluctuations. Peak values of all moments are found in the interfacial layer in the proximity of the top of the CBL. Specifically, water vapour and temperature second-order moments (variance) have maximum values of $0.29 \mathrm{~g}^{2} \mathrm{~kg}^{-2}$ and $0.26 \mathrm{~K}^{2}$; water vapour and temperature third-order moments have peak values of $0.156 \mathrm{~g}^{3} \mathrm{~kg}^{-3}$ and $-0.067 \mathrm{~K}^{3}$, while water vapour and temperature fourth-order moments have maximum values of $0.28 \mathrm{~g}^{4} \mathrm{~kg}^{-4}$ and $0.24 \mathrm{~K}^{4}$. Water vapour and temperature kurtosis have values of $\sim 3$ in the upper portion of the CBL, which indicate normally distributed humidity and temperature fluctuations. Reported values of the higher-order moments are in good agreement with previous measurements at different locations, thus providing 
confidence in the possibility of using these measurements for turbulence parameterisation in weather and climate models.

In the determination of the temperature profiles, particular care was dedicated to minimise potential effects associated with elastic signal crosstalk on the rotational Raman signals. For this purpose, a specific algorithm was defined and tested to identify and remove the elastic signal crosstalk and to assess the residual systematic uncertainty affecting temperature measurements after correction. The application of this approach confirms that, for the present Raman lidar system, the crosstalk factor remains constant with time; consequently an appropriate assessment of its constant value allows for a complete removal of the leaking elastic signal from the rotational Raman lidar signals at any time (with a residual error on temperature measurements after correction not exceeding $0.18 \mathrm{~K})$.

\section{Introduction}

Water vapour and temperature are key meteorological variables which play a major role in the definition of the thermodynamic state of the atmosphere (Wulfmeyer et al., 2015). This is particularly true in the convective boundary layer (CBL), which is an unstable stratified boundary layer that develops in the lower troposphere during the day, dominated by buoyant turbulence generation as a result of strong surface solar heating (Garratt, 1992). Entrainment processes at the top of the CBL are controlled by temperature (capping) inversion in the interfacial layer, ultimately influencing the vertical transport of humidity in the free troposphere (Mahrt, 1991; Sorbjan, 1996; Sullivan et al., 1998; Wulfmeyer et al., 2016). Accurate measurements of water vapour and temperature from the surface to the entrainment zone at the top of the CBL are, therefore, essential for improving weather forecasting (Dierer et al., 2009), reanalyses (Bengtsson et al., 2004) and regional climate simulations (Milovac et al., 2016).

Measurements of higher-order moments of moisture and temperature fluctuations provide unique and essential information for the characterisation of turbulent processes within the convective boundary layer (CBL). Water vapour and temperature variances are key variables in turbulence, convection and cloud parameterisations considered in weather and climate models (e.g. Stull, 1988; Berg and Stull, 2005; Gustafson and Berg, 2007). Within the CBL, water vapour variance increases with height, achieving a maximum at the top of the CBL due to the mixing of moist air in the updraughts with drier air from above the CBL (Wulfmeyer 1999a, b; Kiemle et al., 2007). The water vapour variance profile can also be used to estimate the CBL height and characterise its internal structure by exploiting the tracing capabilities of atmospheric water vapour (among others, Wulfmeyer et al., 2010; Turner et al., 2014a, b). Furthermore, water vapour skewness and kurtosis are found to be characterised by an appreciable vertical variability within the $\mathrm{CBL}$, which changes patterns during the different phases of the CBL evolution (Couvreaux et al., 2005, 2007).

Atmospheric turbulent processes within the CBL have been studied for decades based on the use of in situ sensors (among others, Lenschow and Kristensen, 1985; Kalthoff et al., 2011). However, lidar systems, on the basis of their capability to provide high spatial and temporal resolution and accurate measurements of atmospheric water vapour and temperature, have nowadays reached the level of maturity needed to investigate the relevant atmospheric processes and enable measurements of turbulent variables within the CBL (among others, Eberhard et at., 1989; Frehlich and Cornman, 2002). The major advantage of the lidar techniques is represented by their capability to characterise turbulent variables from the proximity of the surface up to the interfacial layer and above. Additionally, lidar systems can be operated from different platforms and, when applied from ground-based platforms, can provide excellent long-term statistics. This is also necessary for reducing sampling errors, which are usually larger for ground-based than for airborne measurements.

For the characterisation of water vapour turbulent fluctuations, the DIAL and Raman lidar techniques have demonstrated having the temporal and vertical resolution, as well as the accuracy, needed to characterise turbulent processes within the CBL (Wulfmeyer, 1999a, b, 2010; Kiemle et al., 2007; Turner et al., 2014a; Muppa et al., 2016). Profiles of second- to fourth-order moments of turbulent temperature fluctuations in the convective boundary layer have been reported for the first time by Behrendt et al. (2015) based on the application of the rotational Raman lidar (RRL) technique (Behrendt, 2005; Behrendt and Reichardt, 2000; Behrendt et al., 2002; Di Girolamo et al., 2004, 2006; Radlach et al., 2008; Hammann et al., 2015a; Hammann and Behrendt, 2015). Measurements reported in the present paper have been carried out by the Raman lidar system BASIL, exploiting its capability to perform high-resolution and accurate measurements of atmospheric temperature and water vapour, both in the daytime and at night-time and respectively based on the applications of the rotational and vibrational Raman lidar techniques in the UV (Di Girolamo et al., 2004, 2006, 2009a, 2016a; Bhawar et al., 2011). These measurements allow for the determination of the vertical profiles of the turbulent fluctuation of these two atmospheric variables up to the fourth order throughout the atmospheric CBL in the daytime with limited uncertainty. Results from this system are obtained based on the application of the approach introduced by Lenschow et al. (2000), which allows for estimating higher-order moments of turbulent variables in the presence of noisy data. Measurements of water vapour turbulent fluctuations by Raman lidar had been demonstrated by Wulfmeyer et al. (2010), based on the use of the data from the Atmospheric Radiation Measurement (ARM) Raman lidar. Wulfmeyer et al. (2010) came to the conclusion that the noise errors affecting the ARM Raman lidar water vapour mixing ratio measurements 
for the considered case study were too large to derive fourthorder moments with sufficient accuracy. Thus, to the best of our knowledge, BASIL is the first Raman lidar with a demonstrated capability to accurately measure simultaneous daytime profiles of water vapour and temperature turbulent fluctuations up to the fourth order throughout the atmospheric $\mathrm{CBL}$. The main aim of this paper is to provide a detailed characterisation of the performances of the Raman lidar BASIL and demonstrate that profiles of turbulent variables can be determined throughout the CBL with sufficient accuracy. For this purpose measurements from the High Definition Clouds and Precipitation for Climate Prediction $(\mathrm{HD}(\mathrm{CP}) 2)$ Observational Prototype Experiment (HOPE), held in western Germany in spring 2013, are considered.

The paper outline is the following. Section 2 provides a description of the experimental set-up, with details on the data processing and the error analyses; this section also describes the correction scheme considered for removing the elastic signal crosstalk from the low quantum number rotational Raman signal and the uncertainties associated with this approach. Section 3 provides a brief overview of the HOPE field campaign and illustrates the criteria considered for the selection of the case study; this section also illustrates the time-height cross sections of the water vapour mixing ratio and temperature data considered for the turbulence analysis, providing remarks on the meteorological conditions occurring during this period. Section 4 provides a brief description of the methodology considered for the turbulence analysis and illustrates the results achieved in terms of vertical profiles of turbulent variables. Finally, Sect. 5 summarises all results and provides some indications for possible future work.

\section{Experimental set-up}

\subsection{System set-up and derivation of mixing-ratio and temperature profiles}

Prior to HOPE, the University of Basilicata Raman lidar system (BASIL) underwent a substantial upgrade aimed to improve its overall performances in terms of measurement precision and vertical and temporal resolution. These set-up modifications will be described in a separate forthcoming paper (Di Girolamo et al., 2016b). BASIL is a ground-based Raman lidar hosted in a transportable seatainer. The major feature of BASIL is represented by its capability to perform high-resolution and accurate measurements of the vertical profiles of atmospheric temperature and water vapour, both in the daytime and at night-time, based on the application of the rotational and vibrational Raman lidar techniques in the UV (Di Girolamo et al., 2004, 2006, 2009a, 2016a, Bhawar et al., 2011). Besides temperature and water vapour, BASIL is also capable of providing measurements of the vertical profiles of particle backscatter at 354.7, 532 and $1064 \mathrm{~nm}$, par- ticle extinction at 354.7 and $532 \mathrm{~nm}$ and particle depolarisation at 354.7 and $532 \mathrm{~nm}$ (Griaznov et al., 2007; Di Girolamo et al., 2009b, 2012a, b). BASIL is built around a Nd:YAG laser source, equipped with second and third harmonic generation crystals, capable of emitting pulses at 354.7, 532 and $1064 \mathrm{~nm}$, which are simultaneously transmitted in the atmosphere along the zenith. The receiver includes a largeaperture telescope in Newtonian configuration, with a $45 \mathrm{~cm}$ diameter primary mirror and a focal length of $2.1 \mathrm{~m}$, and two small-aperture telescopes $(50 \mathrm{~mm}$ diameter lenses). The radiation collected by the large-aperture telescope is split into eight portions by means of dichroic or partially reflecting mirrors. Specifically, two portions are fed into the detection channels used for temperature measurements (at 354.3 and $352.9 \mathrm{~nm}$ for the low and high quantum number rotational Raman signals, $P_{\mathrm{LoJ}}(z)$ and $\left.P_{\mathrm{HiJ}}(z)\right)$, while two other portions are sent to the water vapour (at $407.5 \mathrm{~nm}$ ) and molecular nitrogen Raman channels (at $386.7 \mathrm{~nm}$ ); corresponding signals are $P_{\mathrm{H}_{2} \mathrm{O}}(z)$ and $P_{\mathrm{N}_{2}}(z)$ in the following. Another two portions of the collected radiation are fed into the 354.7 and $532 \mathrm{~nm}$ elastic channels. A fraction of the signal entering the $354.7 \mathrm{~nm}$ channel is split into two additional portions to allow the detection of the parallel and cross-polarised elastic signals, which are used for the determination particle depolarisation. Signal selection is performed by means of narrowband interference filters, the specifications of which were defined in Di Girolamo et al. (2004, 2009a).

The water vapour mixing ratio $m$ can be obtained from the power ratio of water vapour to molecular nitrogen vibrational Raman signals $\left(m(z)=K(z) \times\left(P_{\mathrm{H}_{2} \mathrm{O}}(z) / P_{\mathrm{N}_{2}}(z)\right)\right)$, where $K(z)=c \cdot f(z)$ is a calibration factor obtained by multiplying several height-dependent correction terms and a heightindependent calibration term, $c$ (e.g. Whiteman, 2003). The height-dependent correction terms, $f(z)$, included in $K(z)$, are a differential transmission term, accounting for the different atmospheric transmission by molecules and aerosols at the two wavelengths corresponding to the water vapour and molecular nitrogen Raman signals, and a term associated with the use of narrowband interference filters and the consequent temperature dependence of $\mathrm{H}_{2} \mathrm{O}$ and $\mathrm{N}_{2} \mathrm{Ra}-$ man scattering signals selected by these filters. The heightindependent calibration factor $c$ is finally obtained from the multiplication of the above-mentioned signal ratio by the height-dependent correction terms, $f(z)$, and the comparison of this quantity with simultaneous and co-located mixing ratio measurements from different sensors (e.g. from radiosondes, microwave radiometers, GPS tomography).

Based on the application of the pure rotational Raman lidar technique, atmospheric temperature is obtained from the power ratio of high-to-low quantum number rotational Raman signals $Q(z)$ through the application of the analytical expression:

$Q(z)=P_{\mathrm{HiJ}}(z) / P_{\mathrm{LoJ}}(z)=\exp (\alpha / T(z)+\beta)$, 
with $\alpha$ and $\beta$ being two calibration constants. Thus we gain the following:

$T(z)=\frac{\alpha}{\ln [Q(z)]-\beta}$.

These two calibration constants can be determined through the comparison of the lidar signal ratio with simultaneous and co-located temperature measurements from different sensors (e.g. from radiosondes, microwave radiometers). The above-considered analytical expression relating $Q(z)$ to $T(z)$ is not the only possible expression, but it is probably the simplest and implies the smallest number of calibration constants. Other more complex analytical expressions have been considered in literature (Behrendt and Reichardt, 2000; Di Girolamo et al., 2004; Behrendt et al., 2015). However, the systematic error associated with assuming the abovecalibration function to be valid for a large portion of the rotational Raman spectrum is found to have a typical amplitude of $0.2 \mathrm{~K}$, which is not relevant for the purposes of the present study (see Wulfmeyer et al., 2016 for an assessment of the effects of systematic errors on turbulence measurements).

During HOPE, water vapour mixing ratio and temperature measurements by BASIL were both calibrated based on a comparison with simultaneous radiosondes, which were launched from the nearby supersite UHOH-KIT, located in Hambach, approx. $4 \mathrm{~km} \mathrm{E-SE}$. All clear-sky radiosonde launches coincident with lidar operation (60 in total) were considered, thus determining 60 distinct values for each calibration coefficient. A mean value for each calibration coefficient was then estimated and used throughout the HOPE period. The comparisons were carried out in a vertical region with an extent of $1 \mathrm{~km}$ located above the boundary layer. This selection allows for minimising the air mass differences related to the physical distance between the lidar and the radiosonde. The variability of the calibration coefficients was found to be very limited throughout the duration of the filed campaign, with single calibration values showing very small deviations from the mean values. For example, concerning water vapour measurements, the standard deviation of single calibration values from the mean calibration coefficient was found to not exceed $5 \%$.

As specified above, BASIL underwent an upgrade before HOPE which allowed for obtaining a substantial improvement of the overall performances in terms of both measurement precision and vertical and temporal resolution. The upgrade included a modification of the optical layout of the Nd:YAG laser source, which allowed a $65 \%$ increase of the emitted power in the UV to be achieved (from an original value of $6 \mathrm{~W}$, single pulse energy of $300 \mathrm{~mJ}$ at $20 \mathrm{~Hz}$, to a final value of $10 \mathrm{~W}$, with a single pulse energy of $500 \mathrm{~mJ}$ at $20 \mathrm{~Hz}$ ). The upgrade also included the implementation of a new sampling system (with double signal acquisition mode, i.e. both analogue and digital) in some of the measurement channels allowing us to acquire daytime and night-time lidar signals with a maximum vertical and temporal resolution of
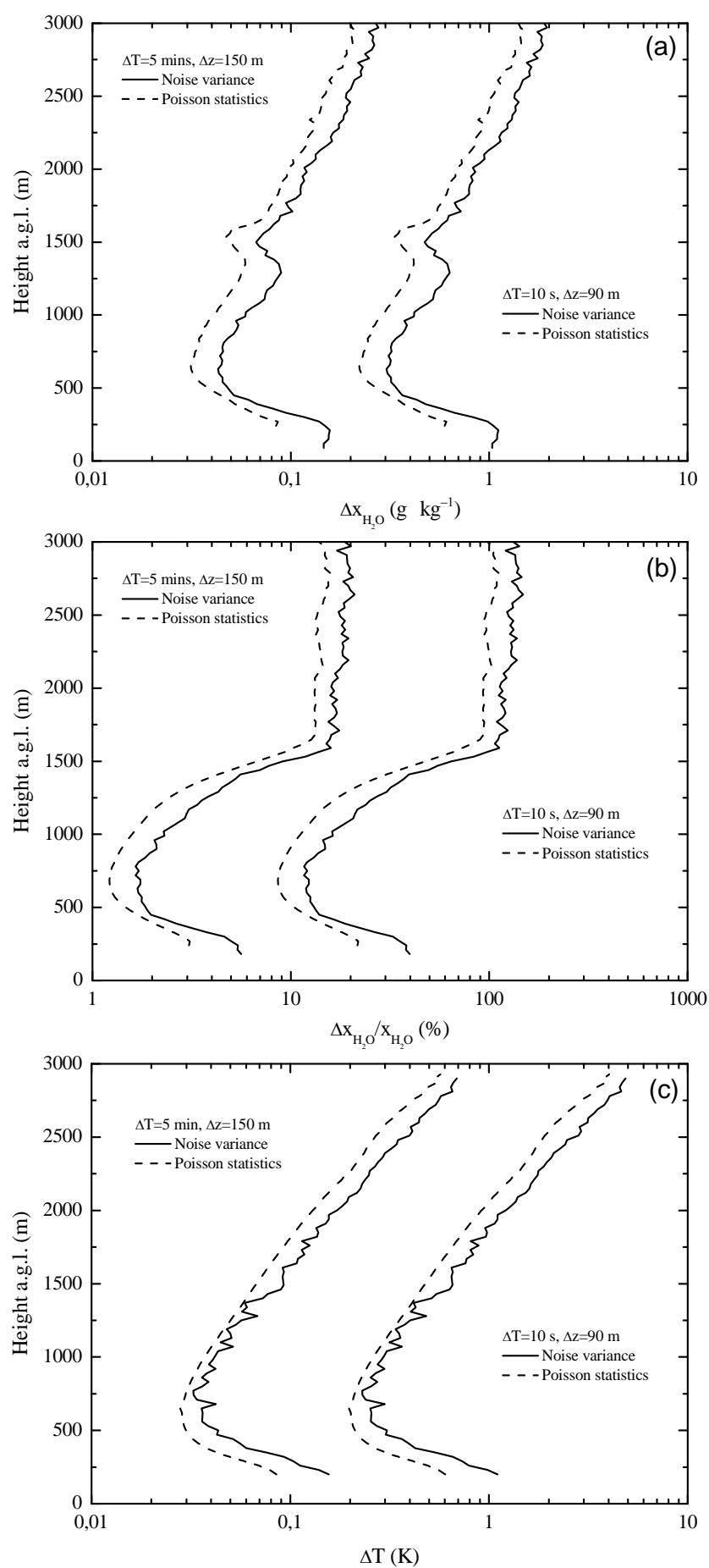

Figure 1. Profiles of noise error affecting water vapour mixing ratio (a and b) and temperature (c) measurements. The figure illustrates the estimates determined based on the application of the autocovariance method, obtained by extrapolating the structure function to lag zero, and the error profiles obtained based on the application of Poisson statistics to signal photon counts. 
$7.5 \mathrm{~m}$ and $1-10 \mathrm{~s}$, respectively. In signal preprocessing, four adjacent data points are binned together to reduce the statistical fluctuations of the signals, increasing the vertical step between adjacent data points to $30 \mathrm{~m}$.

\subsection{Determination of noise errors}

In order to characterise the quality of water vapour mixing ratio and temperature measurements, an accurate assessment of noise error is necessary. Noise error is quantified as the root-square of the noise variance (i.e. the noise standard deviation). Profiles of noise error affecting water vapour mixing ratio and temperature measurements are illustrated in Fig. 1. Specifically, Fig. 1a illustrates the water vapour mixing ratio absolute error (expressed in $\mathrm{g} \mathrm{kg}^{-1}$ ), Fig. $1 \mathrm{~b}$ illustrates the water vapour mixing ratio relative error (expressed in \%), while Fig. 1c illustrates the temperature absolute error (expressed in K). The figure shows the noise error profiles estimated based on the application of the autocovariance method (described in detail in Sect. 4.1). More specifically, noise error assessments have been performed considering two options for temporal and vertical resolution: a higher-resolution configuration, with a temporal resolution of $10 \mathrm{~s}$ and a vertical resolution of 90 and $30 \mathrm{~m}$ for water vapour mixing ratio and temperature, respectively (this is the selection considered for the turbulence measurements) and a lower-resolution configuration, with a temporal resolution of $150 \mathrm{~m}$ and a vertical resolution of $5 \mathrm{~min}$, which is the selection considered for the data set generated and uploaded to the HOPE archive (see Sect. 6, primarily used for verification purposes, process studies and data assimilation). For the first selection, the statistical error affecting water vapour mixing ratio measurements is smaller than $0.6 \mathrm{~g} \mathrm{~kg}^{-1}$ (or $50 \%$ ) up to $1.4 \mathrm{~km}$, while the statistical error affecting temperature measurements is smaller than $1 \mathrm{~K}$ up to $1.8 \mathrm{~km}$. For the second selection, the statistical error affecting water vapour mixing ratio measurements is smaller than $0.1 \mathrm{~g} \mathrm{~kg}^{-1}$ (or $15 \%$ ) up to $1.8 \mathrm{~km}$, while the statistical error affecting temperature measurements is smaller than $0.8 \mathrm{~K}$ up to $3 \mathrm{~km}$. The above-listed performances of BASIL in terms of water vapour mixing ratio measurements are comparable with those reported for the ARM Raman lidar (Wulfmeyer et al., 2010, also $0.6 \mathrm{~g} \mathrm{~kg}^{-1}$ at $1.4 \mathrm{~km}$ ), considering the same temporal and vertical resolution. The same is true for the above-listed performances of BASIL in terms of temperature measurements, which indicate statistical uncertainties with values close to those reported for the ARM Raman lidar (Newsom et al., 2013). The above-quantified errors are used to derive - by means of error propagation - the noise error profiles of the higher-order moments. An overview of these equations is given in Wulfmeyer et al. (2016).

Water vapour mixing ratio and temperature profiles can be derived with different vertical and temporal resolutions depending on the considered application. Vertical and temporal resolutions can be traded-off with measurement precision,

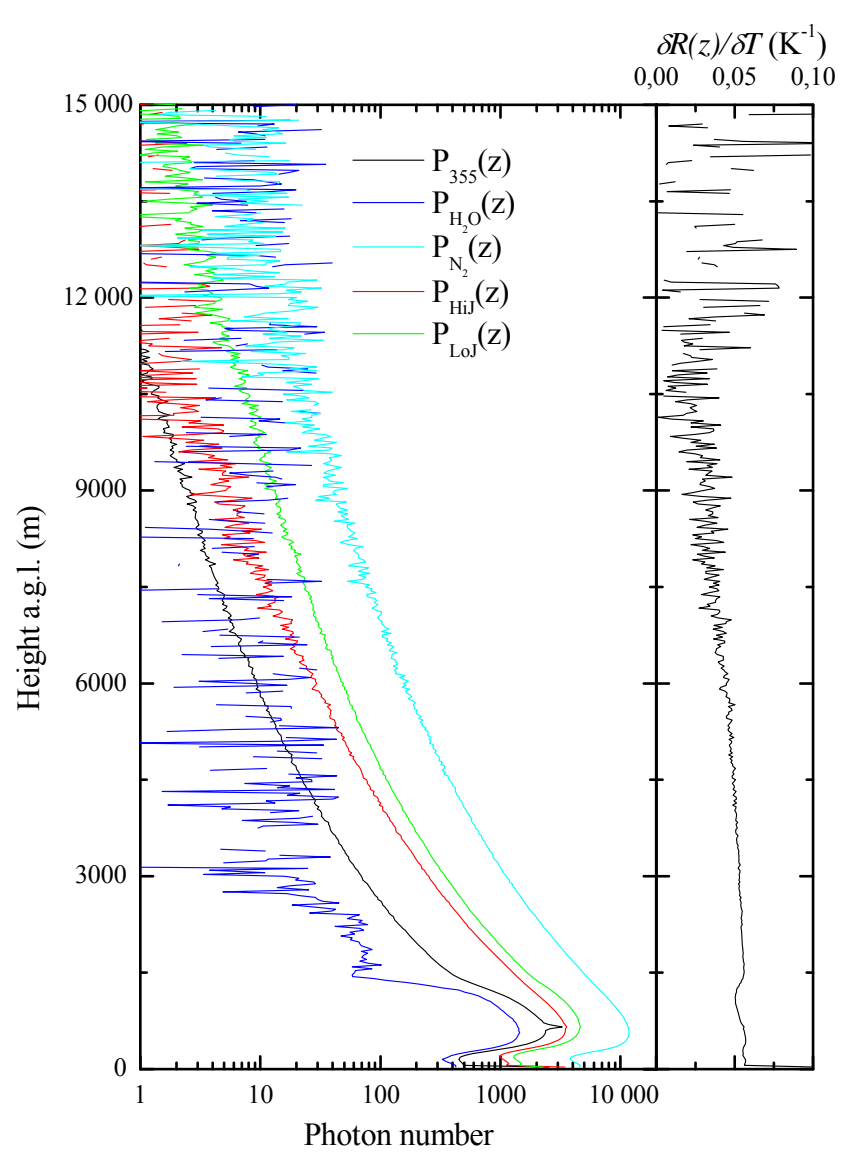

Figure 2. (a) The mean photon numbers (10s average) for the considered signals, i.e. the water vapour and molecular nitrogen vibrational Raman signals, $P_{\mathrm{H}_{2} \mathrm{O}}(z)$ and $P_{\mathrm{N}_{2}}(z)$, the $355 \mathrm{~nm}$ elastic signal, $P_{355}(z)$ and the pure-rotational Raman signals, $P_{\text {LoJ }}(z)$ and $P_{\mathrm{HiJ}}(z)$; (b) temperature sensitivity of RRL measurement technique. $\partial R(z) / \partial T$.

with random error affecting water vapour mixing ratio and temperature measurements being inversely proportional to the square root of both vertical and temporal resolution. Consequently, the consideration of the high temporal and vertical resolutions ( $10 \mathrm{~s}, 30-90 \mathrm{~m}$, respectively) needed for the characterisation of turbulence processes translates into a lower measurement precision (and consequently a larger statistical error). As a result of this, the corresponding statistical error affecting daytime water vapour mixing ratio and temperature measurements is smaller than $100 \%$ and $1 \mathrm{~K}$, respectively, up to $2 \mathrm{~km}$ (Fig. 1), these performances being well suited for lidar measurements finalised to the characterisation of turbulent variables.

Figure 1 also includes the error profiles obtained with the application of Poisson statistics to signal photon counts. Signal photon counts are directly measured by the photon counting unit; "virtual" counts can also be obtained from the signals measured by the analogue module (Newsom et al., 2009). In order to get an estimate of the error affecting water 
vapour mixing ratio and temperature measurements through Poisson statistics, it is necessary to first apply Poisson statistics to the photon counts of the individual lidar signals contributing to the measurements and then, through error propagation, compute the overall error affecting the measured atmospheric variables. The error propagation expression is different for water vapour mixing ratio and temperature measurements as are the analytical expressions relating the individual signals to the two measured parameters. For water vapour mixing ratio measurements the application of error propagation yields the following expression (Di Girolamo et al., 2009a):

$$
\frac{\Delta x_{\mathrm{H}_{2} \mathrm{O}}(z)}{x_{\mathrm{H}_{2} \mathrm{O}}(z)}=\sqrt{\frac{P_{\mathrm{H}_{2} \mathrm{O}}(z)+\mathrm{bk}_{\mathrm{H}_{2} \mathrm{O}}}{P_{\mathrm{H}_{2} \mathrm{O}}^{2}(z)}+\frac{P_{\mathrm{N}_{2}}(z)+\mathrm{bk}_{\mathrm{N}_{2}}}{P_{\mathrm{N}_{2}}^{2}(z)}},
$$

where the terms $b_{\mathrm{H}_{2} \mathrm{O}}$ and $b k_{\mathrm{N}_{2}}$ represent the sky background signal (primarily associated with solar irradiance) collected in the water vapour and molecular nitrogen channels, respectively. Equation (3) provides the relative statistical error (in percentage if multiplied for 100), while the absolute statistical error can be obtained by multiplying Eq. (3) for $x_{\mathrm{H}_{2} \mathrm{O}}(z)$. The mean photon numbers for the $10 \mathrm{~s}$ water vapour and molecular nitrogen vibrational Raman signals, $P_{\mathrm{H}_{2} \mathrm{O}}(z)$ and $P_{\mathrm{N}_{2}}(z)$, displayed in Fig. 2, are found to vary featuring a maximum around $800 \mathrm{~m}$ of approx. 1500 and 12000 counts and progressively decreasing down to 0 and approx. 20 counts around $10 \mathrm{~km}$ (after background subtraction). Here the mean photon number profile is intended as the average of all $10 \mathrm{~s}$ signal profiles collected over the period 11:30-13:30 UT on 20 April 2013. Figure 2 also shows the mean photon number for the $10 \mathrm{~s} 354.7 \mathrm{~nm}$ elastic signal, $P_{354.7}(z)$, which has a maximum of approx. 2200 counts around $800 \mathrm{~m}$ and progressively decreases to 2 counts around $10 \mathrm{~km}$.

For temperature measurements, the application of error propagation yields the expression (Behrendt et al., 2002, 2015; Di Girolamo et al., 2006, 2009a):

$\Delta T(z)=\frac{\partial T(z)}{\partial R} R(z) \sqrt{\frac{P_{\mathrm{LoJ}}(z)+\mathrm{bk}_{\mathrm{LoJ}}}{P_{\mathrm{LoJ}}^{2}(z)}+\frac{P_{\mathrm{HiJ}}(z)+\mathrm{bk}_{\mathrm{HiJ}}}{P_{\mathrm{HiJ}}^{2}(z)}}$,

where the terms $b k_{\mathrm{LoJ}}$ and $b_{\mathrm{HiJ}}$ represent the sky background signal collected in the low- and high-J-rotational Raman channels, respectively. The quantity $\partial T(z) / \partial R$ can be estimated based on the application of the calibration procedure mentioned above. The mean photon numbers for the $10 \mathrm{~s}$ low and high quantum number rotational Raman signals, $P_{\mathrm{LoJ}}(z)$ and $P_{\mathrm{HiJ}}(z)$, also displayed in Fig. 2, are found to vary, featuring a maximum of approx. 4500 and 3500 counts at $800 \mathrm{~m}$, and progressively decreasing down to 8 and 4 counts around $10 \mathrm{~km}$. Figure 2 also shows the temperature sensitivity of the RRL measurement technique, i.e. the quantity $\partial R(z) / \partial T$, which is found to vary between $0.06 \mathrm{~K}^{-1}$ at surface level and approx. $0.03 \mathrm{~K}^{-1}$ at $10 \mathrm{~km}$, and the power ratio of high-to-low quantum number rotational Raman signals, $R(z)$, which is found to vary between approx. 0.8 at surface level and approx. 0.3 at $10 \mathrm{~km}$. The large values of the measurement sensitivity $(\partial R(z) / \partial T)$ contribute to the small random errors affecting the reported temperature measurements.

The terms $b_{\mathrm{H}_{2} \mathrm{O}}$ and $b_{\mathrm{N}_{2}}$ in Eq. (3) and the terms bk $\mathrm{LoJ}_{\mathrm{Lo}}$ and $\mathrm{bk}_{\mathrm{HiJ}}$ in Eq. (4) can be determined from the photoncounting signals at very high heights. In fact, this portion of the signals is characterised by negligible contribution from laser backscatter photons and is typically attributable to sky background radiation and intrinsic detector noise, with the former quantity being much larger than the latter, especially for the daytime operation. For the reported measurements, values of $\mathrm{bk}_{\mathrm{H}_{2} \mathrm{O}}$ and $\mathrm{bk}_{\mathrm{N}_{2}}$ are found to be approx. 11000 and 8000 counts, while values of $b k_{\mathrm{LoJ}}$ and $b_{k_{\mathrm{HiJ}}}$ are found to be approx. 200 and 1000 counts.

It is to be noticed that the autocovariance analysis specifies the total statistical noise, while Poisson statistics accounts only for its shot noise contribution, i.e. the contribution associated with the discrete nature of the photons sampled by photon counting devices. Consequently, the application of Poisson statistics to signal photon counts leads to an underestimation of the total statistical noise (Wulfmeyer et al., 2010; Behrendt et al., 2015). Figure 1 reveals that noise error estimates obtained through the application of Poisson statistics are in good agreement with estimates obtained through the autocovariance approach. Specifically, Poisson statistics account for approximately $75 \%$ of the total statistical noise affecting the measurement of water vapour mixing ratio and temperature. In more detail, Poisson statistics account for 60 to $80 \%$ of the total statistical noise affecting water vapour mixing measurements, with a mean value of $74.5 \%$, while it accounts for 60 to $90 \%$ of the total statistical noise affecting temperature measurements, with a mean value of $78.0 \%$. This confirms that photon shot noise represents the main contribution to the total statistical noise, but other statistical error sources, usually very small, may also contribute.

BASIL performances in terms of the atmospheric variables of interest for the purposes of this paper, extrapolated at higher heights based on the application of Poisson statistics, are as follows. For water vapour mixing ratio measurements, the typical daytime statistical error (precision) is smaller than $20 \%$ up to $3 \mathrm{~km}$ (Fig. 1) and smaller than $100 \%$ up to $4.5 \mathrm{~km}$, while the typical night-time statistical error is smaller than $2 \%$ up to $3 \mathrm{~km}$ (Fig. 1) and smaller than $20 \%$ up to $9 \mathrm{~km}$, based on an integration time of $5 \mathrm{~min}$ and a vertical resolution of $150 \mathrm{~m}$. The statistical error affecting temperature measurements for daytime operation is typically smaller than $0.5 \mathrm{~K}$ up to $3 \mathrm{~km}$ (Fig. 1) and smaller than $1.5 \mathrm{~K}$ up to $4.5 \mathrm{~km}$, while for night-time operation it is typically smaller than $0.4 \mathrm{~K}$ up to $3 \mathrm{~km}$ (Fig. 1) and smaller than $1 \mathrm{~K}$ up to $6.5 \mathrm{~km}$. These error values are consistent with the performances of the ARM water vapour Raman lidar (Wulfmeyer et al., 2010; Turner et al., 2014a). 


\subsection{Systematic errors}

\subsubsection{Time-independent systematic errors}

In addition to the statistical error, a small systematic error (bias) may affect both water vapour and temperature measurements. For example, for water vapour measurements, besides a bias (not exceeding $5 \%$ ) associated with the estimate of the calibration coefficient (resulting from radiosonde biases and different air masses being sounded by the radiosonde and the lidar), an additional very small bias $(<1 \%)$ may be associated with the use of narrowband filters and, consequently, with the accurate estimate of the heightdependent correction factor accounting for the temperature dependence of the $\mathrm{H}_{2} \mathrm{O}$ and $\mathrm{N}_{2}$ Raman scattering signals selected by these filters. At the same time a $1 \%$ systematic uncertainty may be associated with the determination of the differential transmission term (Whiteman, 2003). For temperature measurements, besides a small bias associated with the estimate of the calibration coefficient, an additional small bias $(<0.2 \mathrm{~K})$ is associated with the assumption of the calibration function (1) to be valid for the selected portions of the rotational Raman spectrum. It is to be pointed out that, as the above-mentioned systematic error sources are time independent (see Whiteman, 2003, for water vapour measurements and Sect. 2.3.2 of this paper for temperature measurements), biases can be substantially removed from water vapour and temperature time series measurements based on the use of suitable spectral filters before calculating their fluctuations; consequently, time-independent systematic errors have a marginal influence on the accuracy of turbulence profiles, especially for a high-accuracy system such as ours (see Eqs. A1-A8 in Wulfmeyer et al., 2016).

\subsubsection{Elastic signal crosstalk into the rotational Raman signals and approach for its removal}

Specific check and sensitivity studies have been performed in order to verify the presence and amplitude of elastic signal crosstalks into the rotational Raman signals and their potential effect on temperature measurements. In this respect it can be pointed out that in the present system set-up the low and high quantum number rotational Raman signals, $P_{\mathrm{LoJ}}(z)$ and $P_{\mathrm{HiJ}}(z)$, are collected at 354.3 and $352.9 \mathrm{~nm}$, respectively, these wavelengths being very close to the laser emission at $354.7 \mathrm{~nm}$. Consequently, particular care has to be paid to the definition of the spectral specifications of the interference filters used for the selection of $P_{\mathrm{LoJ}}(z)$ and $P_{\mathrm{HiJ}}(z)$, especially concerning their blocking at $354.7 \mathrm{~nm}$. This is particularly true for the Lo-J filter, having a central wavelength just $0.4 \mathrm{~nm}$ off the excitation wavelength, while it is less for the Hi-J filter, as its central wavelength is $1.8 \mathrm{~nm}$ off the excitation wavelength. The interference filters used in the present system set-up are characterised by a nominal blocking at $354.7 \mathrm{~nm}$ of $10^{-6}-10^{-7}$. However, based on measurements carried out in the presence of clouds, we collected experimental evidence that the effective blocking of our Lo-J filter is not better than $10^{-5}$. For this motivation, in previous field deployments (among others, the Convective and Orographically-induced Precipitation Study - COPS, Wulfmeyer et al., 2008; Behrendt et al., 2011a), a second narrowband interference filter was put in cascade to the Lo-J filter, this second filter having the same central wavelength and passband of the Lo-J filter (the latter is $0.2 \mathrm{~nm}$ full width at half maximum), but having a nominal blocking at $354.7 \mathrm{~nm}$ of $10^{-3}$. The combination of two filters had been successfully applied before at $532 \mathrm{~nm}$, obtaining undisturbed measurements even in clouds (Behrendt and Reichardt, 2000). Just recently, the possibility of achieving sufficient blocking at $354.7 \mathrm{~nm}$ with only one filter could also be demonstrated based on recent advances achieved in multi-cavity interference filter technology (Hammann et al., 2015b). The ultimate goal of using two cascading interference filters was to obtain an overall blocking at $354.7 \mathrm{~nm}$ of $10^{-8}$ or better. However, because of the very narrow passband of the two cascading filters, a perfect superimposition of their transmission curves was found difficult to achieve. In this respect it is to be specified that a partial superimposition of the transmission curves of the two filters may determine an even narrower passband, ultimately compromising the filters' capability to select the rotational lines necessary for the temperature measurements. Additionally, when a perfect superimposition of the two cascading filters' transmission curves is achieved, the overall central wavelength transmission is significantly reduced (not exceeding $15 \%$, with the transmission of the Lo-J filter being $30 \%$ and the transmission of the second cascading filter being $50 \%$ ); thus, the introduction of the second cascading filter determines an overall reduction of $P_{\mathrm{LoJ}}(z)$ by $50 \%$ and a consequent reduction in measurement precision.

In order to avoid these drawbacks, in recent field deployments the second cascading filter was removed from the Lo-J channel, and we were fully aware that this would have determined an overall lower blocking at $354.7 \mathrm{~nm}$ for the Lo-J interference filter and a consequent crosstalk of the $354.7 \mathrm{~nm}$ elastic lidar signal into the Lo-J rotational Raman signal. However, we were also fully aware of the different research efforts and corresponding literature papers dedicated to the definition of approaches to identify and remove elastic signal leakages from the rotational Raman signals (Behrendt et al., 2002; Su et al., 2013). These authors demonstrated that elastic signal crosstalk into the Lo-J rotational Raman signals can be completely removed if simultaneous and co-located measurements of the elastic signal are available. Behrendt et al. (2002) tested their approach on a rotational Raman lidar operating at $532 \mathrm{~nm}$, while Su et al. (2013) applied their approach to a rotational Raman lidar operating at $354.7 \mathrm{~nm}$. At $354.7 \mathrm{~nm}$, the approach considers the following equation:

$P_{\mathrm{LoJ}}(z)=P_{\mathrm{LoJ}}^{\text {leak }}(z)-k T_{\mathrm{F}} P_{354.7}(z)$, 


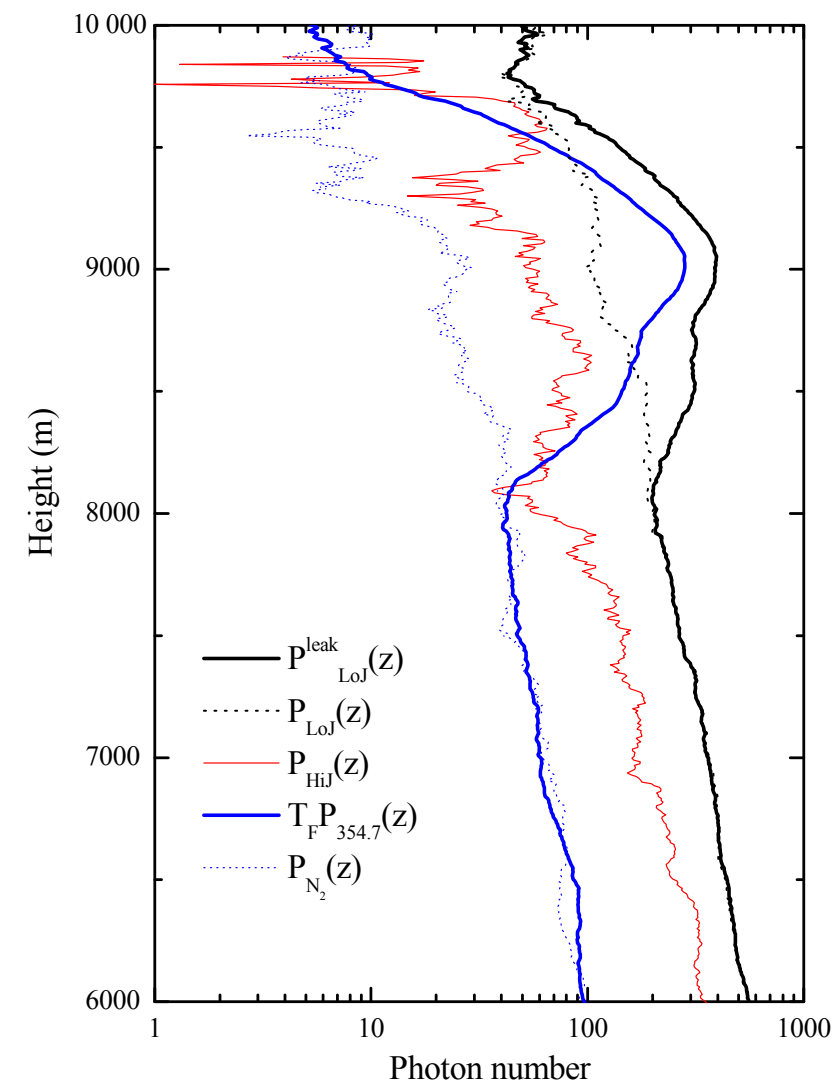

Figure 3. Vertical profiles of $P_{\mathrm{LoJ}}(z), P_{\mathrm{HiJ}}(z), T_{\mathrm{F}} P_{354.7}(z)$ and $P_{\text {LoJ }}^{\text {synt }}(z)$ for the time interval 13:38-13:46 UTC on 20 April 2013, revealing the presence of high cirrus clouds extending between 7.9 and $9.8 \mathrm{~km}$.

with $P_{\text {LoJ }}^{\text {leak }}(z)$ being the leaked Lo-J rotational Raman lidar signal, $P_{\text {LoJ }}(z)$ being the effective Lo-J rotational Raman lidar signal used for the derivation of temperature profiles, $P_{354.7}(z)$ being the $354.7 \mathrm{~nm}$ elastic lidar signal, $T_{\mathrm{F}}$ being the transmission of neutral density filters (used to attenuate the elastic signals and avoid signal induced noise effects associated with the low range echoes), and $k$ being the crosstalk factor. Equation (5) specifies that, if the crosstalk factor is known, the effective Lo-J rotational Raman signal can be determined from leaked Lo-J rotational Raman signal by simply subtracting the $354.7 \mathrm{~nm}$ elastic lidar signal from the latter.

In this respect, it has to be specified that the simultaneity and co-location of the measured Lo-J and 354.7 lidar signals is, in our case, quite a strict requirement, as in fact the signals necessary for the present turbulence studies are acquired with high vertical and temporal resolution. In our system, the simultaneity is guaranteed by the use of two distinct acquisition channels with a common triggering included in a single sampling unit. The co-location of the measurements, i.e. the sounding of the same atmospheric air column, is guaranteed by the use of the same large-aperture telescope for the collec- tion of the two signals and the proximity of the two detection channels within the optical layout of system. In this direction, it is also to be specified that elastic and rotational Raman scattering are stimulated by the same laser wavelength $(354.7 \mathrm{~nm})$ and, consequently, the radiated air column is the same for the two measurement channels.

An accurate estimate of the crosstalk factor $k$ is of paramount importance to remove, or at least minimise, potential systematic errors associated with any residual elastic signal crosstalk into the rotational Raman signals. For this purpose, a modified version of the approach defined by Behrendt et al. (2002) was applied. The approach is based on the selection of a measurement period with clouds, the calculation of $P_{\mathrm{LoJ}}(z)$ for different values of $k$ and the selection of the value of $k$ leading to temperature values inside the cloud best fitting the temperature values from a nearby radiosonde.

For this purpose, we selected a 9 min time interval (13:3813:46 UTC), shortly after the $2 \mathrm{~h}$ time period considered for the turbulence analysis (11:30-13:30 UTC); as a result of this selection, the value of $k$ determined for this time interval can be effectively used to correct the data in the time interval considered in the turbulence analysis. The $9 \mathrm{~min}$ time interval is characterised by the presence of high-level clouds (cirrus clouds) extending between 7.9 and $9.8 \mathrm{~km}$, which are not optically thick, with all measured lidar signals extending above the cloud top. This characteristic makes the selected time interval particularly suited for the estimate of $k$. A 9 min time interval was considered in order to achieve sufficiently high signal statistics and, consequently, a low uncertainty in the determination of the correct value of $k$ based on the abovementioned best fit procedure. Figure 3 shows the vertical profiles of $P_{\mathrm{LoJ}}^{\text {leak }}(z), P_{\mathrm{HiJ}}(z)$ and $T_{\mathrm{F}} P_{354.7}(z)$ averaged over the 9 min interval. To better illustrate the proposed approach, in Fig. 3 we focused our attention on the vertical interval 6$10 \mathrm{~km}$. The elastic signal $P_{354.7}(z)$ reveals the presence of several layers associated with cirrus clouds between 7.9 and $9.8 \mathrm{~km}$, with a peak at $9.3 \mathrm{~km}$. The figure clearly highlights the elastic signal crosstalk into $P_{\mathrm{LoJ}}^{\text {leak }}(z)$ in the height region inside the cloud, while no evidence of elastic signal crosstalk is present in $P_{\mathrm{HiJ}}(z)$ in this same height region. To apply the best fit procedure, the radiosonde launched at 13:00 UTC from the nearby launching station in Hambach (approx. $4 \mathrm{~km}$ E-SE) was used. Considering an ascent speed of $3.5 \mathrm{~m} \mathrm{~s}^{-1}$, which is the average speed experienced by the present radiosonde in the height interval from surface up to $10 \mathrm{~km}$, the radiosonde is expected to cover the $8-10 \mathrm{~km}$ height region in the time interval 13:38-13:46 UTC, which is exactly the time interval considered for the application of our approach. The value of $k$ leading to temperature values inside the cloud best fitting the radiosonde temperature values was found to be 0.91 . The best fit procedure considers all data points (approx. 70 points) within the height range where the cirrus cloud is located $(7.9$ and $9.8 \mathrm{~km})$. This computation was repeated at different times during the presence of cirrus clouds (12:22-18:52 UTC), also considering the data from 
the additional radiosondes available in this period (i.e. at 15:00 and 17:00 UTC). Results reveal that $k$ has a constant value of 0.91 , with very limited dispersion $(0.01)$ around this value, i.e. $k \pm \Delta k=0.91 \pm 0.01$ (Nocera, 2016). This result demonstrates that laser frequency or the filter's position fluctuations, potentially generable by thermal drifts inside the laser cavity or the filter's housing, respectively, have negligible effects on $k$.

It should be pointed out that crosstalk correction increases the statistical uncertainty affecting the temperature measurement as a result of the subtraction of $P_{354.7}(z)$, which is affected by statistical noise, from $P_{\mathrm{LoJ}}^{\text {leak }}(z)$, also affected by statistical noise, the two statistical noises being uncorrelated. Additionally, the correction factor $k$ is determined with a certain degree of uncertainty (small, but not negligible), which may lead to a residual systematic error (bias) affecting temperature measurements after the application of the crosstalk correction approach. The systematic error associated with this residual crosstalk may be estimated through error propagation, using the equation for $T(z)$ including crosstalk correction:

$$
T(z)=\frac{\alpha}{\ln \left[\frac{P_{\mathrm{HiJ}}(z)}{P_{\mathrm{LoJ}}^{\text {leak }}(z)-k T_{\mathrm{F}} P_{354.7}(z)}\right]-\beta},
$$

with $T_{\mathrm{F}}$ being the overall transmission $\left(\sim 10^{-3}\right)$ of the two neutral density filters located in front of the $354.7 \mathrm{~nm}$ interference filter. Consequently, the systematic error affecting each temperature profile associated with the uncertainty affecting $k$ reads as follows:

$$
\begin{aligned}
& \Delta T_{\text {leak }}(z) \\
& =-\frac{T^{2}(z)}{\alpha} \frac{k T_{\mathrm{F}} P_{354.7}(z)}{P_{\mathrm{LoJ}}^{\text {leak }}(z)-k T_{\mathrm{F}} P_{354.7}(z)} \frac{\Delta k}{k} \\
& \cong-\frac{T^{2}(z)}{\alpha} \frac{k T_{\mathrm{F}} P_{354.7}(z)}{P_{\mathrm{LoJ}}^{\text {leak }}(z)} \frac{\Delta k}{k} \\
& =-\frac{T^{2}(z)}{\alpha} \frac{T_{\mathrm{F}} P_{354.7}(z)}{P_{\mathrm{LoJ}}^{\text {leak }}(z)} \Delta k
\end{aligned}
$$

with $\Delta k$ being the uncertainty affecting the estimate of $k$. The crosstalk signal is $k T_{\mathrm{F}} P_{354.7}(z)$, which corresponds to about $22 \%$ of $P_{\mathrm{LoJ}}^{\text {leak }}(z)$ around the ABL top. Thus, the remaining error affecting temperature measurements becomes a fluctuating error, which is dependent on atmospheric properties, mainly on aerosol backscatter contribution to $P_{354.7}(z)$. This effect has to be properly taken into account in the determination of turbulence profiles, as in fact fluctuations in aerosol particle backscatter, especially in the upper portion of the CBL, may produce a time-dependent residual systematic error, which could propagate into the temperature fluctuations. Because of this, the quantity $P_{\mathrm{LoJ}}(z)=P_{\mathrm{LoJ}}^{\text {leak }}(z)-$ $k T_{\mathrm{F}} P_{354.7}(z)$ has to be properly assessed in Eq. (6) for each $10 \mathrm{~s}$ temperature profile.
Considering an uncertainty of 0.01 on the estimate of $k$, a value of $T=280 \mathrm{~K}$, a value of $\alpha=1200 \mathrm{~K}$ (which is the one resulting from the application of the calibration procedure), the systematic error $\Delta T_{\text {leak }}(z)$ associated with residual crosstalk in the upper portion of the CBL is equal to $0.18 \mathrm{~K}$.

An additional overall, spurious term $\overline{\left(T_{\mathrm{ov} \text {, leak }}(z)\right)^{2}}$ also has to be considered in the temperature variance, which is associated with the residual systematic error affecting temperature measurements after the application of the crosstalk correction approach. This additional contribution is given by the following:

$$
\begin{aligned}
& \overline{\left(T_{\text {ov, leak }}{ }^{\prime}(z)\right)^{2}} \approx \overline{\Delta T_{\text {leak }}{ }^{\prime 2}}+2 \overline{T_{\text {tr }}{ }^{\prime}(t) \Delta T_{\text {leak }}{ }^{\prime}(t)} \\
& <\overline{\Delta T_{\text {leak }}{ }^{\prime 2}}+2 \sqrt{\overline{\Delta T_{\text {leak }}{ }^{\prime 2}}} \sqrt{\overline{{T_{\text {tr }}{ }^{\prime 2}}^{2}}}
\end{aligned}
$$

where the first term is the contribution to the "crosstalk variance" due to additional fluctuations caused by insufficient crosstalk correction and the second term is due to the correlation of the atmospheric temperature fluctuations within the not perfectly corrected crosstalk. We find the following:

$$
\begin{aligned}
\overline{\Delta T_{\text {leak }}{ }^{\prime 2}} & \cong\left[\frac{T^{2}}{\alpha}\right]^{2} \frac{\left(k T_{\mathrm{F}}\right)^{2} \overline{\left(P_{354.7}(t)-\bar{P}_{354.7}\right)^{2}}}{\left(\bar{P}_{\text {Loo }}^{\text {leak }}-k T_{\mathrm{F}} \bar{P}_{354.7}\right)^{2}}\left(\frac{\Delta k}{k}\right)^{2} \\
& =\left[\frac{T^{2}}{\alpha}\right]^{2} \frac{\left(k T_{\mathrm{F}} \bar{P}_{354.7}\right)^{2}}{\left(\bar{P}_{\text {LoJ }}^{\text {leak }}-k T_{\mathrm{F}} \bar{P}_{354.7}\right)^{2}}\left(\frac{\Delta k}{k}\right)^{2} \\
& \frac{\left(P_{354.7}(t)-\bar{P}_{354.7}\right)^{2}}{\bar{P}_{354.7}^{2}} \\
& =\left(\Delta T_{\text {leak }}\right)^{2} \frac{\overline{\left(P_{354.7}(t)-\bar{P}_{354.7}\right)^{2}}}{\bar{P}_{354.7}^{2}} \\
& =\left(\Delta T_{\text {leak }}\right)^{2} \frac{\operatorname{var}\left(\bar{P}_{354.7)}\right.}{\bar{P}_{354.7}^{2}} \\
& \approx(0.18 \mathrm{~K})^{2} \frac{1.7 \cdot 10^{4}}{500^{2}}=2.2 \cdot 10^{-3} \mathrm{~K}^{2},
\end{aligned}
$$

where we took the relative amplitude and variance of the backscatter signal from our data at the ABL top. Here, the variance is maximum so that we reach an upper limit of the spurious temperature variance of $2.2 \times 10^{-3} \mathrm{~K}^{2}$ which can be neglected with respect to the atmospheric temperature variance (see Sect. 4.3). For the correlation term, however, we get

$$
\begin{aligned}
& 2 \overline{T_{\text {tr }}^{\prime}(t) \Delta T_{\text {leak }}^{\prime}(t)}<2 \sqrt{\overline{\Delta T_{\text {leak }}{ }^{\prime 2}}} \sqrt{\overline{{T_{\text {tr }}^{\prime \prime}}^{\prime 2}}} \\
& \approx 2 \cdot 0.048 \mathrm{~K} \cdot 0.64 \mathrm{~K}=0.06 \mathrm{~K}^{2},
\end{aligned}
$$

where we took the maximum of the atmospheric temperature variance at the ABL top. This error is still consider- 
ably smaller than our estimate of the atmospheric temperature variance at the peak in the entrainment layer so that the structures in the higher-order moments are significant.

Based on the above considerations, we have to be aware that, besides a random error represented in Fig. $6 \mathrm{~b}$ with the error bar, an additional systematic error (with a maximum amplitude of $0.18 \mathrm{~K}$ ) resulting from residual elastic signal crosstalk into the rotational Raman signals has to be considered. This is also true for the noise error estimated in Fig. 1c. The missed inclusion of this systematic error both in Figs. 6b and $1 \mathrm{c}$ is due to the very small amplitude of this contribution; additionally, random and systematic error sources have always to be treated separately and cannot be just summed up. The spurious temperature variance, even if small with respect to the atmospheric temperature variance, is always positive. So an iteration with different values for $k$ can also be used to verify the correctness of the above-determined value of $k$, as in fact the correct value minimizes the overall variance.

Based on the above-mentioned approach, before proceeding with the turbulence analysis, we corrected all $10 \mathrm{~s} \mathrm{Lo-J}$ signals for the systematic effect associated with elastic signal crosstalk. However, in order to overcome the residual systematic uncertainty associated with this correction, a future upgrade of BASIL is planned with the introduction of a new Lo-J filter, with high blocking at $354.7 \mathrm{~nm}$ and high central wavelength transmission, to be developed benefiting from the recent advances in multi-cavity interference filter technology.

\section{Time-height cross sections of water vapour mixing ratio and temperature}

\subsection{Case study and weather conditions}

In this paper we illustrate measurements carried out in the framework of the $\mathrm{HD}(\mathrm{CP}) 2$ Observational Prototype Experiment (HOPE). HOPE, embedded in the project HighDefinition Clouds and Precipitation for advancing Climate Prediction (HD(CP)2) of the German Research Ministry, was specifically designed to provide a data set for the evaluation of the German non-hydrostatic general circulation model ICON at the scale of the model simulations. It took place in western Germany in the time period April-May 2013. For the purposes of HOPE, BASIL was deployed in the Supersite JOYCE, located within the Jülich Research Centre (Central Germany, Lat.: 50 54' N; Long.: $6^{\circ} 24^{\prime}$ E, Elev. $105 \mathrm{~m})$. The system operated between 25 March and 31 May 2013, collecting more than $430 \mathrm{~h}$ of measurements distributed over 44 days and 18 IOPs. Quick-looks from this data set are present on the HOPE Website (https://code. zmaw.de/projects/hdcp2-obs/), while water vapour and particle backscatter data can be downloaded from the $\mathrm{HD}(\mathrm{CP}) 2$ database.

In the selection of the case study considered in this paper, attention was paid to identifying weather conditions charac-

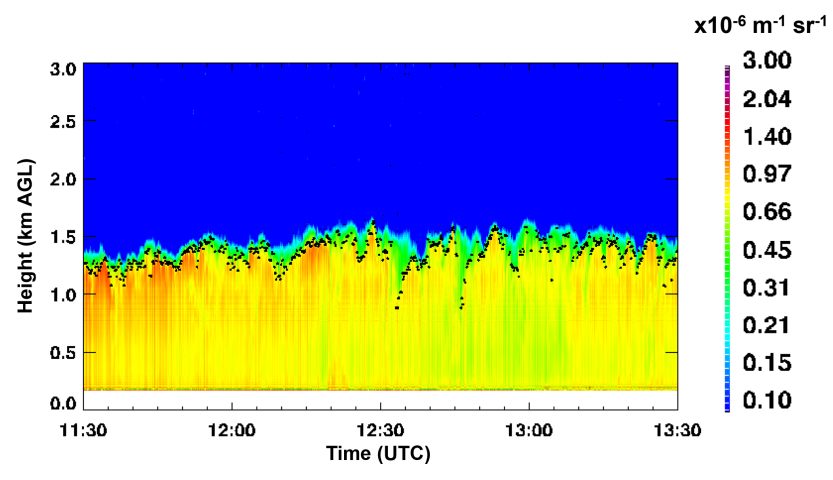

Figure 4. Time-height cross section of the particle backscatter coefficient, $\beta_{\text {par }}$, between 11:30 and 13:30 UTC on 20 April 2013. The black line in the figure identifies the CBL height $z_{i}$.

terised by the presence of a well-mixed and quasi-stationary CBL. Consequently, in those cases when measurements of the complete CBL cycle are available, i.e. from the onset to its progressive build-up and final decay, attention has been focused only on those time segments characterised by a stable or almost stable CBL height, which corresponds to the period of its maximum development. Typically time segments with a duration of $1-2 \mathrm{~h}$ are used as for longer periods the CBL can no longer be considered as being quasistationary, while shorter periods would reduce the number of sampled thermals and thus increase the sampling errors, affecting all turbulent variables.

The synoptic condition on 20 April 2013 was characterised by the presence of a high-pressure system located over Great Britain, with effects extending over north-central Germany, and a low-pressure system located over central Italy (see also Muppa et al., 2016). The forecast for the HOPE region indicated some thin convective clouds from 8:00 to 10:00 UTC and clear sky starting from 10:00 UTC, with cirrus clouds starting from 15:00 UTC. This was considered as a day with suitable atmospheric conditions for an Intensive Observation Period (IOP), specifically IOP 5, dedicated to radiometer tomography. This IOP turned out to be also a good case study for the purpose of studying CBL development under clearsky or almost clear-sky conditions. Indeed, the almost undisturbed solar irradiance resulted in the development of a wellmixed CBL which was not affected by clouds.

\subsection{Water vapour mixing ratio, temperature and backscatter fields}

In order to select an appropriate time interval for the application of the turbulence analysis, we considered the measurements of the different energy balance components as provided by the surface energy balance station in Hambach (not illustrated here). The maximum net radiation was found to occur around 12:00 UTC $\left(520 \mathrm{Wm}^{-2}\right)$, with a very limited variability $\left(<40 \mathrm{Wm}^{-2}\right)$ within the time interval 11:30- 

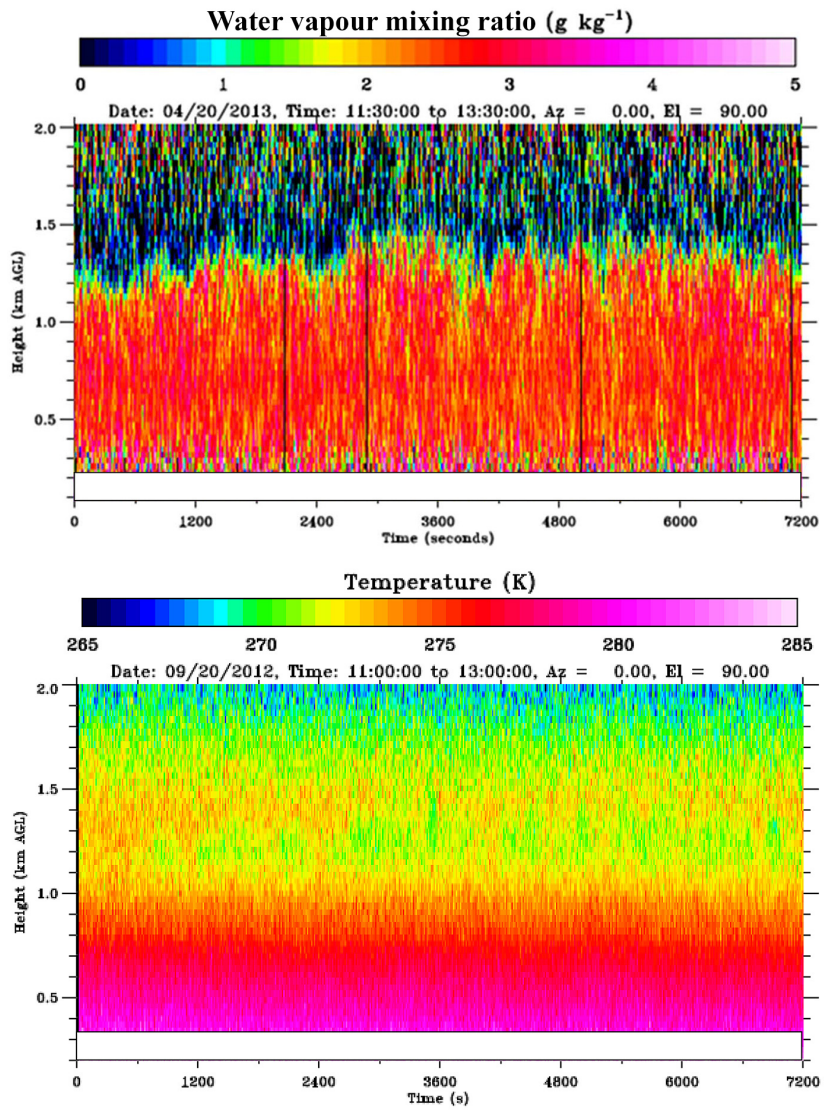

Figure 5. Time-height cross section of water vapour mixing ratio (a) and temperature (b) in the same time interval considered in Fig. 4.

13:30 UTC. This is the time interval that we selected for the turbulence analysis.

In order to achieve a sufficiently high signal-to-noise ratio (SNR) and, consequently, an acceptably low noise error level, a running average over 3 points was considered for the water vapour mixing ratio data, which translates into a reduced vertical resolution of $90 \mathrm{~m}$. No average was applied to the temperature data, keeping the original vertical resolution of $30 \mathrm{~m}$.

Figure 4 illustrates the time-height plot of the particle backscatter coefficient at $1064 \mathrm{~nm}, \beta_{\mathrm{par}}$, between 11:30 and 13:30 UTC on 20 April 2014. The figure reveals the presence of a significant aerosol loading within the boundary layer (with values of $\beta_{\mathrm{par}}$ in the range $0.3-1.4 \times 10^{-6} \mathrm{~m}^{-1} \mathrm{sr}^{-1}$ ), tracing the presence of a well-mixed and quasi-stationary CBL at this time of the day, extending up to a height of approximately $1300 \mathrm{~m}$. The figure also reveals the presence of alternating updraughts and downdraughts. $\beta_{\text {par }}$ was determined based on the application of a Klett-modified approach (Di Girolamo et al., 1995, 1999). The identification of the CBL height and the monitoring of its variability is made possible by exploiting aerosols to act as atmospheric tracers.
The mean CBL height, $z_{i}$, is an important scaling variable for turbulence profiles. The evolution of the instantaneous CBL height $z_{i}^{\prime}$ (black dots in Fig. 4) was determined through the application of a conventional approach based on the detection of the strongest gradient in the aerosol backscatter signal (see, among others, Pal et al., 2010; Haeffelin et al., 2012; Milroy et al., 2012; Summa et al., 2013). Within the considered time interval, $z_{i}^{\prime}$ is found to be characterised by a limited variability, with a mean value $z_{i}$ of $1290 \mathrm{~m}$ a.g.l, and a standard deviation of $75 \mathrm{~m}$. The minimum and maximum values of $z_{i}^{\prime}$ during the observation period are 1140 and $1440 \mathrm{~m}$ a.g.l., respectively. This result is in very good agreement with the simultaneous measurements performed by the University of Hohenheim Differential Absorption Lidar (UHOH-DIAL; Wagner et al., 2013; Späth et al., 2016), deployed in Hambach, approx. $4 \mathrm{~km}$ E-SE, with a mean value of $1295 \mathrm{~m}$ and a standard deviation of $86 \mathrm{~m}$ (Muppa et al., 2016). $z_{i}$ is used in the remaining part of the paper to determine the normalised height scale $z / z_{i}$. Particle backscatter coefficient data can also be used to identify the presence of aerosol layers and/or clouds within and above the CBL, with an effective demonstrated capability to detect cloud bases and tops (the latter in the case of cloud optical thickness typically smaller than 2, Di Girolamo et al., 2009b).

Figure 5 illustrates the time-height cross section of water vapour mixing ratio (Fig. 5a) and temperature (Fig. 5b) for the same time interval considered in Fig. 4. Figure 5a and b clearly highlights the large variability of water vapour mixing ratio and temperature within the CBL associated with the presence of alternating updraughts and downdraughts. The largest variability of both water vapour mixing ratio and temperature is observed in the interfacial layer, as a result of the penetration of the warm humid air rising from the ground and the entrainment of cool dry air from the free troposphere. Figure $5 \mathrm{~b}$ also reveals the presence of decreasing temperatures within the CBL up to a minimum around $1200-1300 \mathrm{~m}$ and an appreciable temperature inversion (approx. $1 \mathrm{~K}$ ) above.

Figure 6 illustrates the mean profile for water vapour mixing ratio (Fig. 6a) and temperature (Fig. 6b) as measured by BASIL over the same time interval considered in Fig. 4 (11:30-13:30 UTC on 20 April 2013), together with the corresponding profiles measured by the radiosonde launched at 13:00 UTC from the nearby site of Hambach. The water vapour mixing ratio profiles from BASIL and the radiosonde are found to agree within $0.2 \mathrm{~g} \mathrm{~kg}^{-1}$ in the mixed layer. A larger deviation is found in the interfacial layer $\left(0.5 \mathrm{~g} \mathrm{~kg}^{-1}\right)$. However, this is not surprising when considering that the Raman lidar data are averaged over a $2 \mathrm{~h}$ period (11:30 13:30 UTC), while the radiosonde reaches the CBL top a few minutes after launch. Besides the different time interval considered for BASIL and the radiosonde, the two sensors also sound different air masses as a result of the $4 \mathrm{~km}$ distance between the lidar site and the radiosonde launching station and the horizontal drift of the sonde during its ascent caused by 

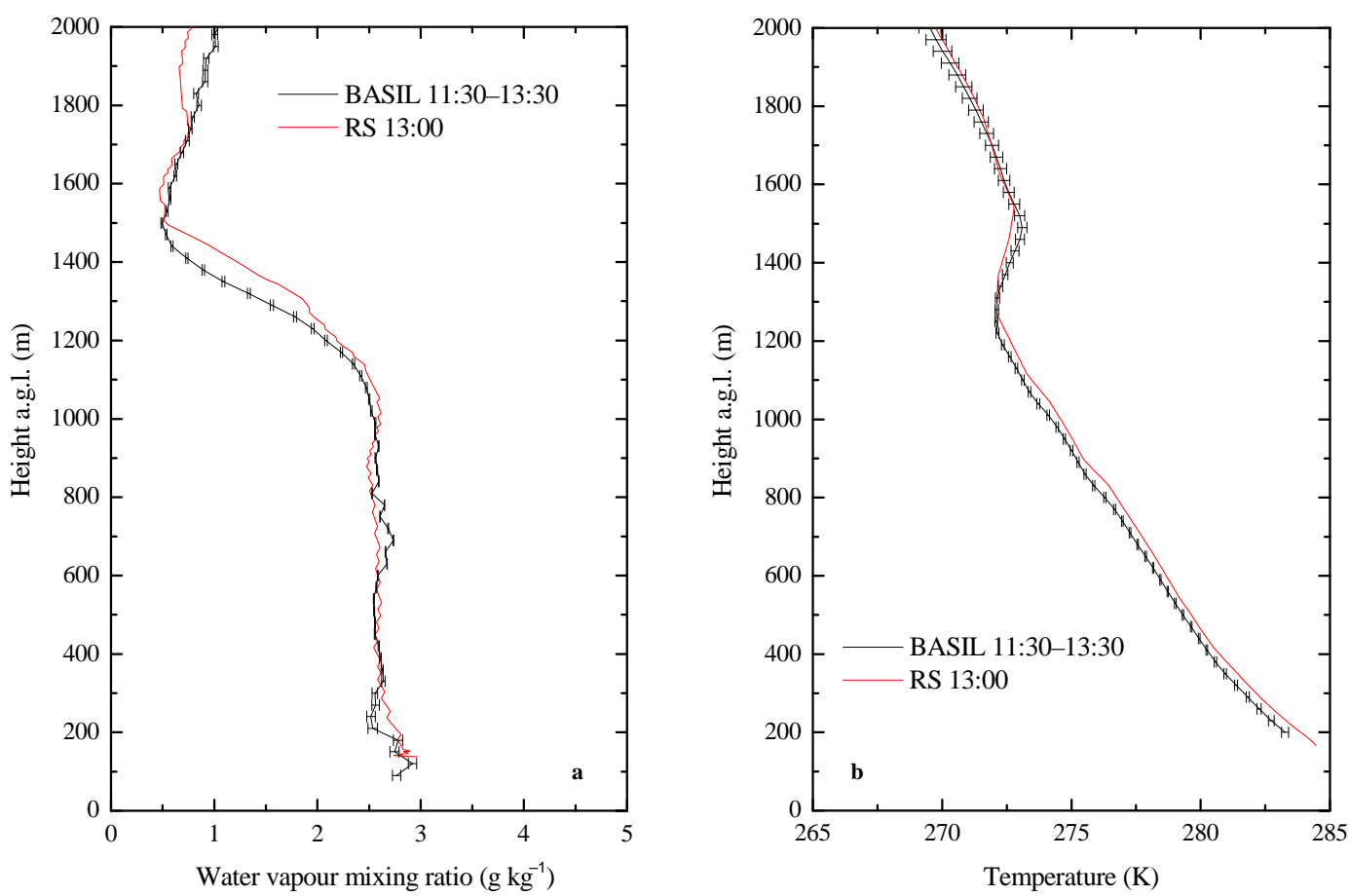

Figure 6. Mean water vapour mixing ratio (a) and temperature (b) profiles measured by BASIL on 20 April 2013 between 11:30 and 13:30 UTC, together with the corresponding profiles as measured by a radiosonde launched at 13:00 UTC from the nearby site of Hambach. Noise error bars are also shown.

the wind and the consequent deviation of its atmospheric path from the vertical. In the presence of intense convective activity, deviations from the sounding data are also possible for radiosondes launched from the lidar site. In this case humid air updraughts and dry air downdraught may have lengths of a few kilometres; consequently the radiosonde can capture different features during its ascent within the CBL with respect to the lidar. This property makes lidar systems much more suitable for studying turbulence statistics than in situ sounding systems. In fact, because of the capability of the former to monitor the vertical air column above the station as opposed to radiosondes undergoing a horizontal drift during their ascent and, consequently, a deviation from the vertical, lidar systems guarantee the capability to measure turbulence statistics within the turbulent eddies involved in the boundary layer mixing processes. Similar considerations apply to the comparison between BASIL and the radiosonde in terms of temperature profile (Fig. 6b). In this case, the deviation between the two sensors is $\cong 0.5 \mathrm{~K}$ throughout the $\mathrm{CBL}$, with BASIL being characterised by systematically smaller values than the radiosonde, while a better agreement (deviation not exceeding $0.3 \mathrm{~K}$ ) is observed in the free troposphere above the CBL top. In this respect, it is to be noticed that the sequence of consecutive radiosondes launched during IOP 5 (at 09:00, 11:00, 13:00 UTC, not shown here) reveals the occurrence of vertical profiles characterised by an almost constant potential temperature values within the mixed layer, as expected for a well-mixed CBL, with potential temperature constant value progressively increasing with time. Considering that Raman lidar data in Fig. 6 are averaged over a $2 \mathrm{~h}$ period (11:30-13:30 UTC) which is largely anticipating the radiosonde launch time (at 13:00 UTC), the systematically smaller temperature values of BASIL with respect to the radiosonde within the CBL are easily justifiable.

\section{Turbulence analysis methodology and results}

\subsection{Methodology}

In CBL turbulence studies, the instantaneous value of a measured atmospheric variable, $x(z, t)$, at height $z$, can be expressed as the sum of three terms: a slowly varying or even constant term, $\overline{x(z)}$, where the overbar represents the time average over the considered temporal interval for the turbulence analysis, a fluctuation or perturbation term, $x^{\prime}(z, t)$ and a system noise term, $\varepsilon(z, t)$, following the equation:

$x(z, t)=\overline{x(z)}+x^{\prime}(z, t)+\varepsilon(z, t)$.

$\overline{x(z)}$ can be derived by applying a linear fit to the data over the time period when the turbulent processes are studied (typically $60-120 \mathrm{~min}, 120 \mathrm{~min}$ in our case).

Here the fluctuation term $x^{\prime}(z, t)$ represents the detrended fluctuation term with zero mean. To detrend the data within 
a CBL in a quasi-stationary state, a linear fit is applied to the atmospheric variable time series.

For any measured atmospheric variable, as atmospheric variance and the noise variance are uncorrelated, total variance can be expressed as follows (Lenschow et al., 2000):

$\overline{\left(x_{\mathrm{m}}{ }^{\prime}(z)\right)^{2}}=\overline{\left(x_{\mathrm{a}}{ }^{\prime}(z)\right)^{2}}+\overline{\left(x_{\mathrm{n}}{ }^{\prime}(z)\right)^{2}}$,

with $\overline{\left(x_{\mathrm{m}}{ }^{\prime}(z)\right)^{2}}$ being the total measured variance, $\overline{\left(x_{\mathrm{a}}{ }^{\prime}(z)\right)^{2}}$ being the atmospheric variance and $\overline{\left(x_{\mathrm{n}}{ }^{\prime}(z)\right)^{2}}$ being the noise variance.

Different procedures may be considered to separate atmospheric variance from noise variance in the total measured variance. The autocovariance method is probably the most effective and straightforward among these procedures. This method is based on the consideration that atmospheric fluctuations are correlated in time, while instrumental noise fluctuations are uncorrelated (Lenschow et al., 2000). This approach allows us to determine atmospheric variance based on the computation of the autocovariance function (ACF) for the considered atmospheric variable and then extrapolating this function to zero lag based on the application of a powerlaw fit. As specified in Lenschow et al. (2000), the autocovariance function at zero lag represents the total measured variance and, consequently, the noise variance can be determined as the difference between the autocovariance function extrapolated to zero lag and its value at zero leg.

An alternative approach is represented by the spectral method. In this case, the power spectrum of the atmospheric variable fluctuations is computed and the constant white noise level close to the Nyquist frequency is evaluated. Both the spectral method, based on the assumption that the system noise is white, and the autocovariance method allow us to verify whether the major part of the turbulent fluctuations is resolved through the measurements, either by comparing the high-frequency component of the spectrum with the theoretical decay in the inertial subrange or by fitting the turbulent structure function to the autocovariance function. Thus, there is no reason to transfer the data in the spectral domain for these applications and, because of that, the data analysis was kept in the time domain. Furthermore, while both approaches were considered and tested on the water vapour and temperature data in this paper, the autocovariance technique (see Fig. 1) is to be preferred because of its capability to directly determine system noise variance by means of the Fourier transformation of the autocovariance function, without introducing additional uncertainties (Wulfmeyer et al., 2010).

Preliminary preprocessing steps have to be applied to the data before both techniques can be applied. In general, before any further processing, spikes must be detected and flagged, as they negatively affect the calculation of turbulent variables (Senff et al., 1996). In fact, the presence of spikes in the time series may have a significant impact on the computations of higher-order moments of the turbulent statistics. Spikes in water vapour and temperature profiles primarily result from non-linear effects associated with the application of retrieval algorithms, these being likely to happen especially at low signal-to-noise levels (Di Girolamo et al., 2008). Low signalto-noise levels are typically found in the daytime Raman lidar water vapour and temperature measurements at heights above $3-5 \mathrm{~km}$. This height varies depending on the considered variable (being lower for water vapour and higher for temperature) or in the presence of clouds as a result of the laser beam attenuation. For the application considered in this paper, i.e. the characterisation of turbulent processes within the CBL, the vertical range of interest is up to $2000 \mathrm{~m}$, and within this range the signal-to-noise level of rotational and vibrational Raman signals is typically large enough to refrain from applying the spike removal algorithm to the data. Additionally, for the specific case study considered in this paper, clouds are completely missing within the CBL; consequently the application of the spike removal algorithm to the lidar data returns a data set with almost no data removed. However, there may be missing data or data gaps generated in the adaptation of the temporal resolution; because of this, a spike detection algorithm (McNicholas and Turner, 2014) is routinely applied to the data before either the autocovariance method or the spectral method are applied.

\subsection{Turbulent fluctuations and corresponding autocovariance functions}

Figure 7 illustrates the time-height cross section of water vapour mixing ratio (Fig. 7a) and temperature fluctuations (Fig. 7b) in the same time interval considered in Fig. 4. Positive and negative humidity and temperature fluctuations are present within the CBL. In the interfacial layer, the fluctuations become larger than they were below. More specifically, instantaneous water vapour fluctuations are within \pm 0.5 in the mixed layer and $\pm 1 \mathrm{~g} \mathrm{~kg}^{-1}$ in the interfacial layer, while instantaneous temperature fluctuations are within $\pm 0.5 \mathrm{~K}$ in the mixed layer and $\pm 1 \mathrm{~K}$ in the interfacial layer. In the free troposphere humidity and temperature fluctuations are almost completely missing and the observed variability is primarily driven by instrumental noise.

Figure 8 shows the autocovariance functions obtained from water vapour (Fig. 8a) and temperature fluctuations (Fig. 8b) for the height levels between 400 and $1600 \mathrm{~m}$ a.g.l., i.e. 0.3 to $1.25 z_{i}$, and for lags from -200 to 200 s. As mentioned earlier, the difference between the peak at zero lag and the first lag provides an estimate of the system noise variance. This is also described in Fig. 8a and b, where the structure functions have been fitted to the autocovariance functions at 1230 and $1410 \mathrm{~m}$ to verify the feasibility and reliability of this approach. In the figure, this difference is found to increase with height for both variables as a result of the increasing system statistical noise. Values of the ACFs close to the zero lag provide an estimate of the atmospheric variance: larger values for the ACFs found in the figure at 1230 

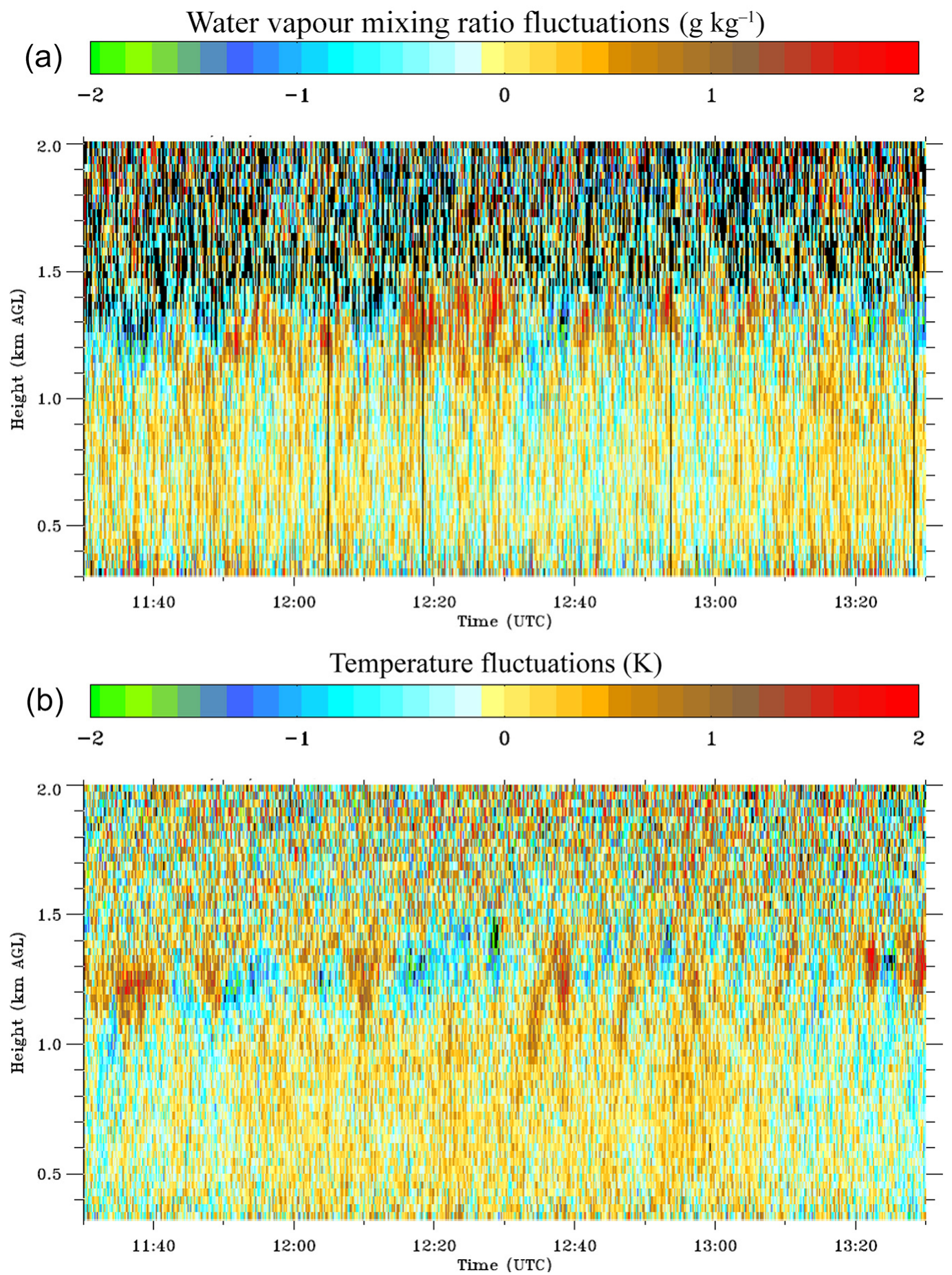

Figure 7. Time-height cross section of water vapour mixing ratio (a) and temperature fluctuations (b) in the same time interval considered in Fig. 4.

and $1410 \mathrm{~m}$ indicate a larger atmospheric variance at these heights, as a result of the large atmospheric variability within the interfacial layer.

\subsection{Measurements of higher-order moments}

Figure 9 illustrates the integral scale (IS) of water vapour mixing ratio (Fig. 9a) and temperature fluctuations (Fig. 9b) computed for the same time interval considered in Fig. 4. 

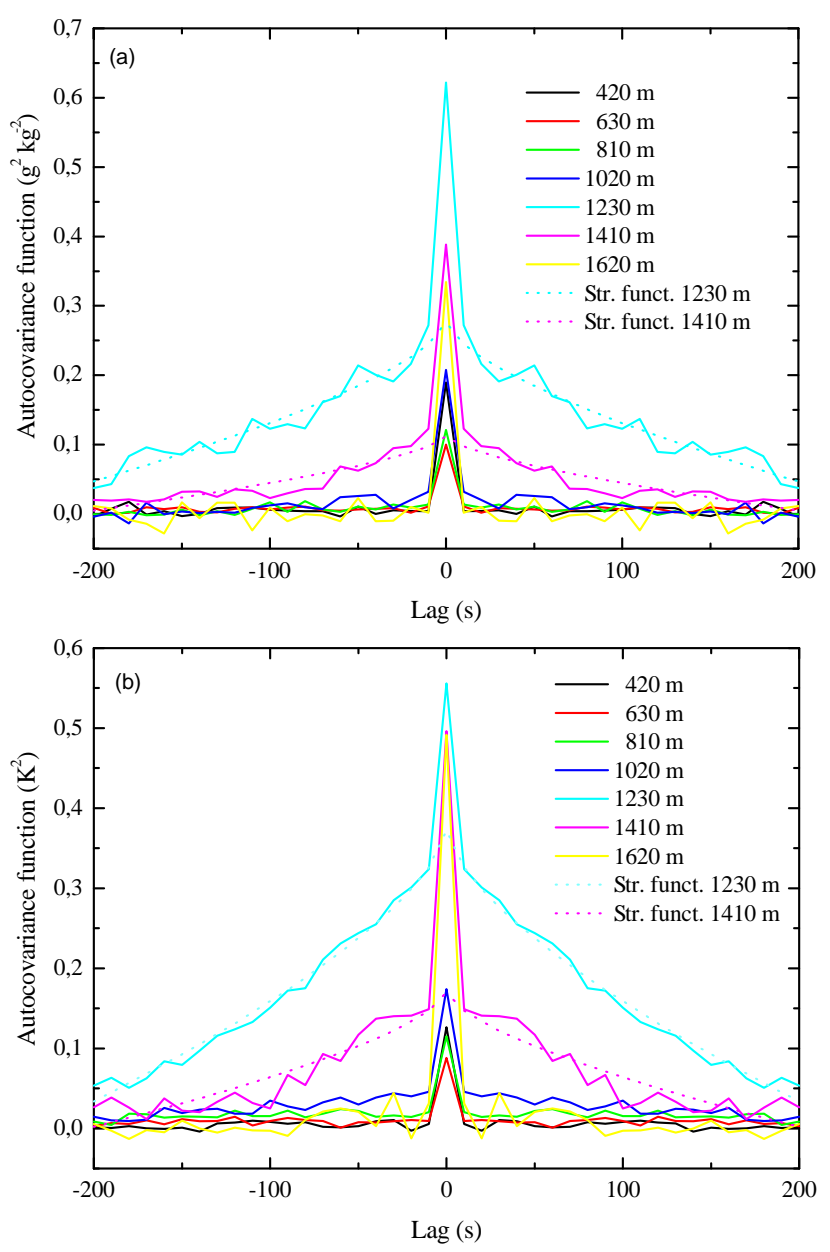

Figure 8. Autocovariance functions obtained from the measured water vapour mixing ratio (a) and temperature (b) fluctuations in the same time interval considered in Fig. 4. Autocovariance functions are displayed for the height levels between 400 and $1600 \mathrm{~m}$ a.g.l., i.e. 0.3 to $1.25 z_{i}$, for lags from -200 to $200 \mathrm{~s}$.

The integral scale can be considered an estimate of the mean size of the turbulent eddies involved in the boundary layer mixing processes. The integral scale of both water vapour mixing ratio and temperature fluctuations is found to have large values (also in excess of 200, up to $500 \mathrm{~s}$ for water vapour) in the lower portion of the CBL up to $\cong 750 \mathrm{~m}$ (i.e. $\left.z / z_{i}<0.6\right)$. Values of the integral scale for water vapour mixing ratio fluctuations in the upper portion of the CBL (above $750 \mathrm{~m}$ ) are in the range $70-125 \mathrm{~s}$, with a peak value of $125 \mathrm{~s}$ at $1230 \mathrm{~m}$ (i.e. $z / z_{i}=0.95$ ). These values are in agreement with those reported for water vapour by Wulfmeyer et al. (2010, 70-130 s) and by Turner et al. (2014a, 120-140), as well as with the simultaneous nearby measurements performed by the UHOH-DIAL, with values in the range 60-130 s (Muppa et al., 2016). Values of the integral scale for temperature fluctuations in the upper portion of the CBL are in the range $75-225 \mathrm{~s}$, with a peak value of $225 \mathrm{~s}$ around the top of the
CBL (at $1310 \mathrm{~m}$ ). These values are in agreement with those reported by Behrendt et al. $(2015,40-120 \mathrm{~s})$ in a different case study, for the nearby site of Hambach. Values of the integral scale throughout the CBL for both water vapour and temperature fluctuations are much larger than the temporal resolution used for the measurements $(10 \mathrm{~s})$, which demonstrates that the considered temporal resolution is high enough to characterise the major part of turbulence inertial subrange and, consequently, resolve the major part of the CBL turbulent fluctuations.

Figure 10 shows the vertical profiles of atmospheric and total variance for water vapour mixing ratio (panel a) and temperature (panel b), including noise errors. Water vapour mixing ratio variance is almost zero up to $\cong 750 \mathrm{~m}$ (i.e. $\left.z / z_{i}=0.6\right)$. It remains small $\left(<0.05 \mathrm{~g}^{2} \mathrm{~kg}^{-2}\right)$ in the middle and upper portion of the CBL $(750 \mathrm{~m}<z<1100 \mathrm{~m}$, i.e. $0.6<z / z_{i}<0.85$ ), and it significantly increases in the interfacial layer due to the entrainment effects. The maximum of the variance profile in the interfacial layer is $0.287 \mathrm{~g}^{2} \mathrm{~kg}^{-2}$ at $1260 \mathrm{~m}$ (i.e. $z / z_{i}=0.98$ ), with 0.051 and $0.034 \mathrm{~g}^{2} \mathrm{~kg}^{-2}$ being the sampling error and noise error, respectively. The near-zero values in the lower portion of the CBL are typical and indicate weak forcing from the surface. In the interfacial layer, the variance reaches a maximum as a result of the large water vapour mixing ratio variability which is generated by the vertical exchange associated with the strong updraughts and downdraughts (Wulfmeyer et al., 2010; Turner et al., 2014a; Muppa et al., 2016). Variance values at the top of the CBL are in good agreement with those reported by Wulfmeyer (1999a, b, 0.1-0.2 $\mathrm{g}^{2} \mathrm{~kg}^{-2}$ ), Lenschow et al. (2000, 0.1-0.2 $\mathrm{g}^{2} \mathrm{~kg}^{-2}$ ) and Kiemle et al. (1997, 0.3$0.45 \mathrm{~g}^{2} \mathrm{~kg}^{-2}$ ), as well as with the simultaneous nearby measurements by the UHOH-DIAL, with a peak value in the interfacial layer of $0.39 \mathrm{~g}^{2} \mathrm{~m}^{-6}$, corresponding to $0.19 \mathrm{~g}^{2} \mathrm{~kg}^{-2}$. The full width at half maximum of peak variance in the entrainment zone is $240 \mathrm{~m}$, i.e. $0.19 z / z_{i}$, in agreement with measurements reported by Wulfmeyer et al. $\left(2010,0.16 z / z_{i}\right)$ and by Turner et al. $\left(2014 \mathrm{a}, 0.15 z / z_{i}\right)$. Values of water vapour mixing ratio variance decrease above the CBL top to approach zero around $1500 \mathrm{~m}$.

The temperature variance remains smaller than $0.1 \mathrm{~K}^{2}$ in the middle and upper portion of the CBL up to 1150 (i.e. $\left.z / z_{i}<0.9\right)$. Larger values are observed in the interfacial layer, with a maximum of $0.260 \mathrm{~K}^{2}$ at $1310 \mathrm{~m}$ (i.e. $z / z_{i}=1.02$ ), with 0.051 and $0.035 \mathrm{~K}^{2}$ for the sampling error and noise error, respectively. Larger values of the temperature variance in the interfacial layer are the result of the penetration of the warm humid air rising from the ground and the entrainment of cool dry air from the free troposphere (Stull, 1988; Behrendt et al., 2015; Wulfmeyer et al., 2016). Temperature variance decreases above the CBL top to approach zero around $1450 \mathrm{~m}$. The full width at half maximum of peak variance in the entrainment zone is $240 \mathrm{~m}$, i.e. $z / z_{i}=0.2$. Similar peak variance values $\left(0.40 \mathrm{~K}^{2}\right)$ at the top of the CBL were also observed by Behrendt et al. (2015) and Wulfmeyer 

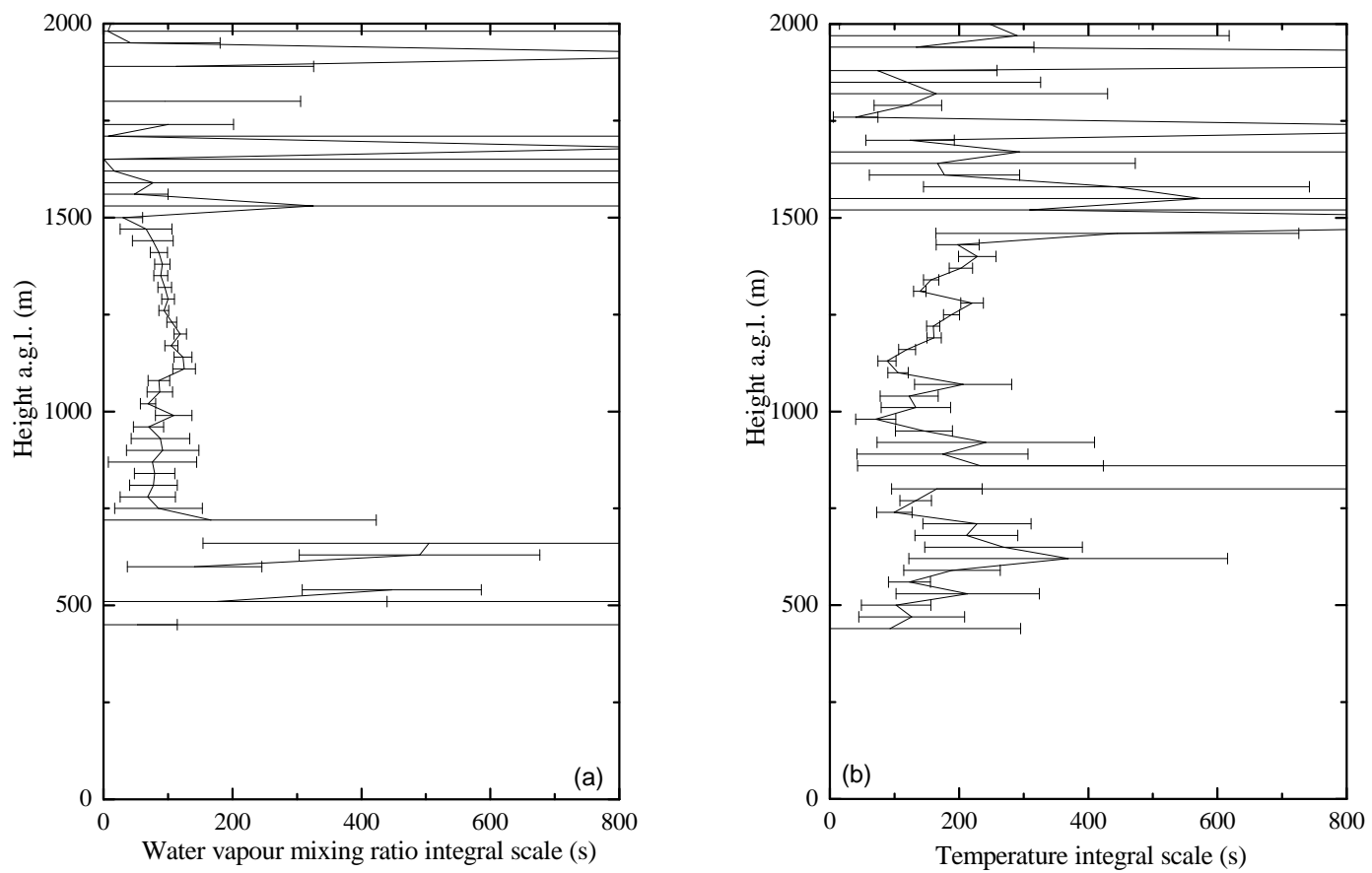

Figure 9. Integral scale of water vapour mixing ratio (a) and temperature fluctuations (b) computed for the same time interval considered in Fig. 4.
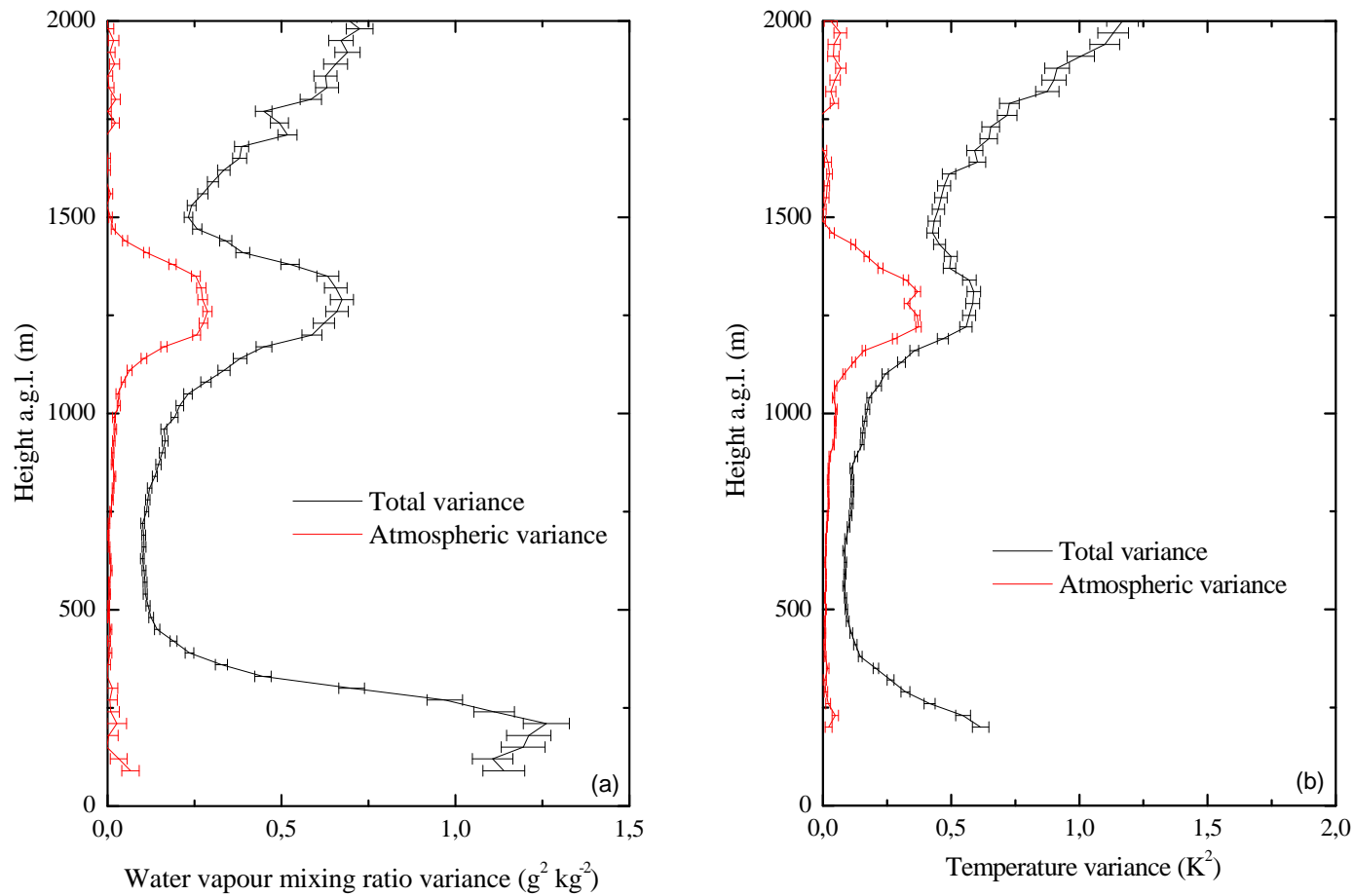

Figure 10. Vertical profiles of atmospheric and total variance for water vapour mixing ratio (a) and temperature (b) computed for the same time interval considered in Fig. 4. In the figure the error bars represent only the noise error.

et al. (2016). It is to be noticed that both water vapour mixing ratio and temperature variance are characterised by very small sampling and noise errors, which makes the quality of the present turbulence measurements very high and demonstrates how well the structures present in these profiles can be determined. 

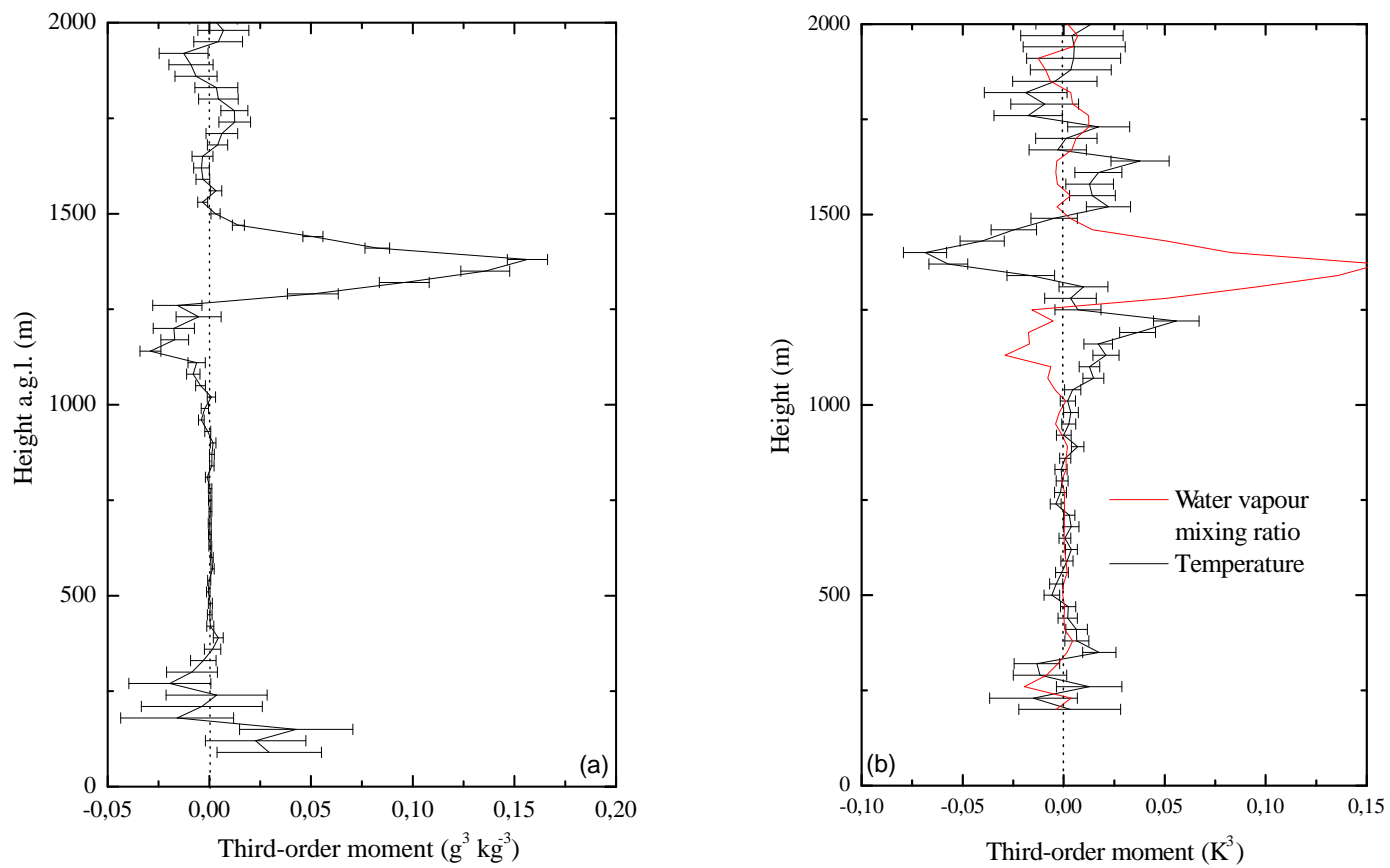

Figure 11. Vertical profiles of the third-order moment for water vapour mixing ratio (a) and temperature (b) computed for the same time interval considered in Fig. 4. In the figure the error bars represent only the noise error.

Figure 11 illustrates the vertical profiles of the third-order moment for water vapour mixing ratio (panel a) and temperature (panel $b$ ). The third-order moment of a variable quantifies the degree of asymmetry of its distribution, with positive values indicating a right-skewed distribution (with the mode smaller than the mean) and negative values indicating a leftskewed distribution (with the mode larger than the mean). Again, third-order moment estimates are characterised by very small errors, which testify the high quality of the present measurements of this turbulent variable. In Fig. 11 values of the third-order moment of water vapour mixing ratio fluctuations are found to be close to zero between 400 and $900 \mathrm{~m}$ (i.e. for $0.3 z_{i}<z<0.7 z_{i}$ ) and are negative between 900 and $1290 \mathrm{~m}$ (i.e. for $0.7 z_{i}<z<z_{i}$ ), with a negative peak value of $-0.029 \pm 0.005 \mathrm{~g}^{3} \mathrm{~kg}^{-3}$ at $1140 \mathrm{~m}$. A large positive peak is observed just above the CBL top, with a maximum of $0.156 \pm 0.009 \mathrm{~g}^{3} \mathrm{~kg}^{-3}$ at $1380 \mathrm{~m}\left(z=1.07 z_{i}\right)$.

Negative values for the water vapour mixing ratio thirdorder moment in the upper portion of the CBL is the result of the sharp entrainment of dry air pockets into the boundary layer, which gradually mix with the environmental air (Couvreux et al., 2005, 2007; Wulfmeyer et al., 2010, 2016; Turner et al., 2014a). Positive values for the water vapour mixing ratio third-order moment above the top of the CBL are associated with narrow, but strong, convective plumes that penetrate up to this height. The sign and shape of the third-order moment at the top of the boundary layer may also depend on the humidity gradient above the CBL (Couvreux et al., 2007). The near-zero third-order moment values in the mixed layer $\left(z / z_{i}<0.7\right)$ are attributable to a symmetric transport process of moisture (Mahrt, 1991; Wulfmeyer et al., 2010).

The temperature third-order moment shows values close to zero $\left(<0.01 \mathrm{~K}^{3}\right)$ up to $1100 \mathrm{~m}\left(z / z_{i}<0.85\right)$ and slightly positive values between 1100 and $1310 \mathrm{~m}\left(0.85 z_{i}<z<1.02 z_{i}\right)$, with a positive peak of $0.055 \mathrm{~K}^{3}$ at $1220 \mathrm{~m}$. Above $1250 \mathrm{~m}$ it becomes negative, with a negative peak of $-0.067 \pm 0.01 \mathrm{~K}^{3}$ at $1400 \mathrm{~m}\left(z / z_{i}=1.1\right)$. The structure of this moment is basically inverted with respect to water vapour (Behrendt et al., 2015). This makes sense because the water vapour gradient is negative in the entrainment zone, whereas the temperature inversion gradient is positive. The positive peak in the interfacial layer is evidence of the predominant effect of narrow warm air downdraughts in the interfacial layer, while the negative peak above the CBL top is the result of narrow cooler updraughts above the CBL top associated with thermals from the surface. Figure 11b, besides the temperature third-order moment, includes the vertical profile of the water vapour mixing ratio third-order moment to better compare the shapes and locations of the peaks and zero crossing values for these two profiles. This reveals that the negative peak in the temperature third-order moment appears at the same height (within $20 \mathrm{~m}$ ) of the positive peak in the water vapour mixing ratio third-order moment, while the distance between the zero crossing values for the two profiles is approx. $100 \mathrm{~m}$.

Figure 12 illustrates the vertical profiles of the fourthorder moment for water vapour mixing ratio (panel a) and temperature (panel $b$ ). The fourth-order moment of a vari- 

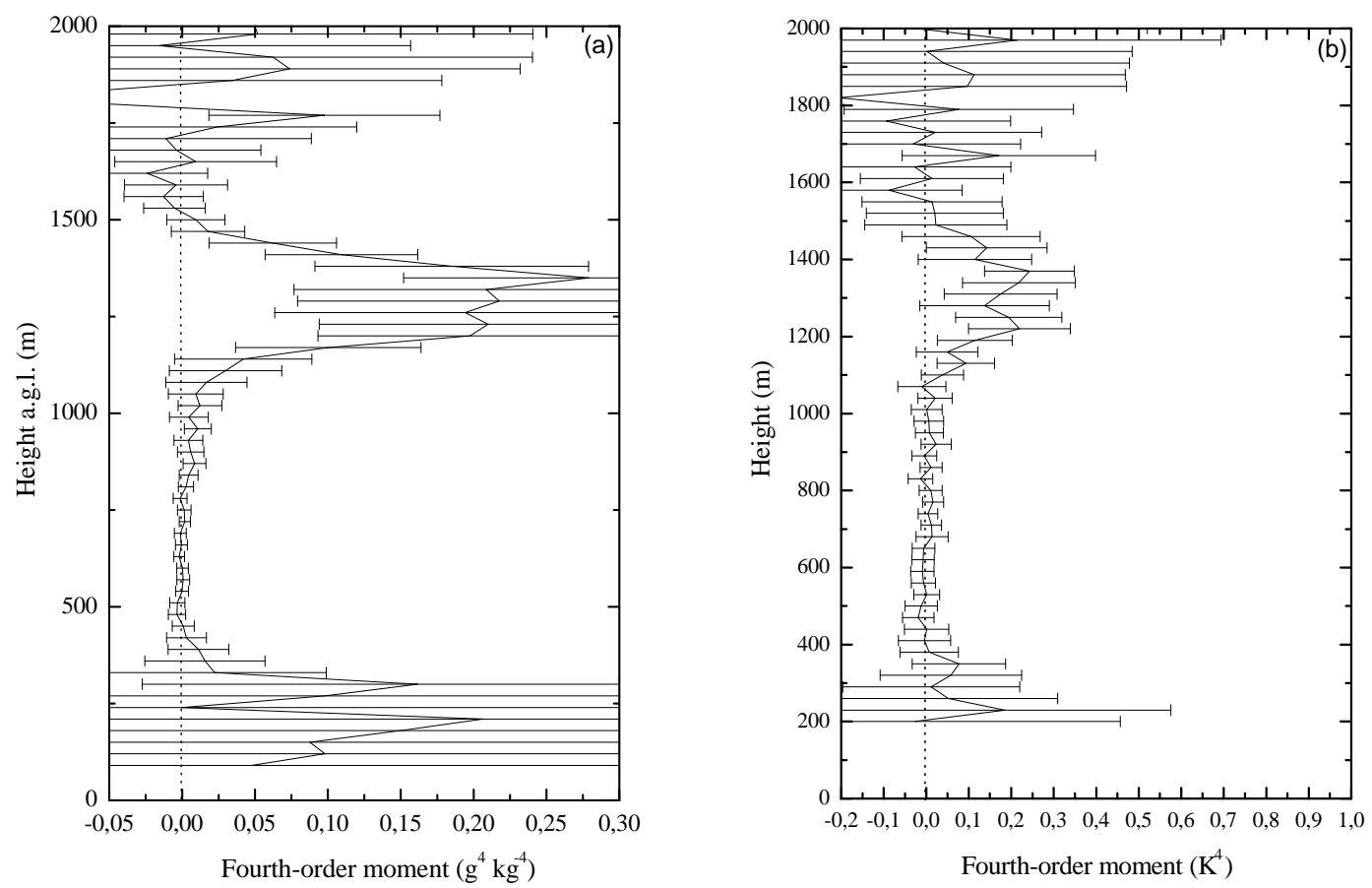

Figure 12. Vertical profiles of the fourth-order moment for water vapour mixing ratio (a) and temperature (b) computed for the same time interval considered in Fig. 4. In the figure the error bars represent only the noise error.

able gives an indication of the steepness of its distribution and the width of its peak. Water vapour mixing ratio fourth-order moment is almost zero up to $\cong 750 \mathrm{~m}$ (i.e. $z / z_{i}=0.6$ ), remains smaller than $0.02 \mathrm{~g}^{4} \mathrm{~kg}^{-4}$ in the middle and upper portion of the CBL $(750 \mathrm{~m}<z<1100 \mathrm{~m}$, i.e. $0.6<z / z_{i}<0.85$ ) and increases above $1100 \mathrm{~m}$, reaching its maximum of $0.28 \pm 0.13 \mathrm{~g}^{4} \mathrm{~kg}^{-4}$ around the top of the CBL (at $1350 \mathrm{~m}$ ). It gets again close to zero above $1530 \mathrm{~m}$. Similarly, temperature fourth-order moment is almost zero $\left(<0.05 \mathrm{~K}^{4}\right)$ up to $1100 \mathrm{~m}$ (i.e. $\left.z / z_{i}=0.85\right)$ and has positive values above, reaching a positive peak of $0.24 \pm 0.10 \mathrm{~K}^{4}$ ) around the top of the CBL (at $1370 \mathrm{~m}$, i.e. $z / z_{i}=1.06$ ). Again, it becomes smaller than $0.05 \mathrm{~K}^{4}$ above $1500 \mathrm{~m}$ (i.e. $\left.z / z_{i}=1.15\right)$.

Besides the third- and fourth-order moments, atmospheric skewness and kurtosis have been determined for both water vapour mixing ratio and temperature fluctuations. Figure 13 illustrates the vertical profiles of skewness (panel a) and kurtosis (panel b) for water vapour mixing ratio and temperature. Values of water vapour mixing ratio skewness are in very good agreement with those reported by Wulfmeyer et al., 2010, with positive values (up to 1.5) in the lower portion of the CBL (up to $800 \mathrm{~m}$, i.e. $z / z_{i}=0.65$ ) and negative values (down to -1 ) in the middle and upper portion of the CBL $\left(800<z<1290 \mathrm{~m}\right.$, i.e. $\left.0.65<z / z_{i}<1.00\right)$. Large positive values are found within the entrainment zone and just above the CBL top (with a maximum of approx. 5 at $1400 \mathrm{~m}$, i.e. $z / z_{i}=1.15$ ), which testifies the presence of humidity fluctuations strongly deviating from a normal distribution. Values and vertical structure of water vapour mixing ratio skewness are also in good agreement with the simultaneous and nearby measurements performed by the UHOH-DIAL (Muppa et al., 2016), with negative values (down to -1.16 ) in the middle and upper portion of the CBL $\left(0.35<z / z_{i}<1.00\right)$ and positive values just above the PBL top (with a maximum of approx. 1 at $z / z_{i}=1.05$ ). They also agree with the measurements reported by Turner et al. (2014a), with negative values (down to $\sim-1$ ) up to the CBL top, zero values around $z_{i}$ and positive values just above the CBL top (with a maximum of approx. 1 at $z / z_{i}=1.1$ ).

Temperature skewness has a negative peak $(\sim-4)$ at $500 \mathrm{~m}$, i.e. $z / z_{i}=0.4$, positive peaks $(\sim 8$ and 4$)$ at 890 and $1100 \mathrm{~m}$ (i.e. $z / z_{i}=0.7$ and $z / z_{i}=0.85$ ) and negative values within the entrainment zone and just above the CBL top (with a peak value of $\sim-7$ at $1460 \mathrm{~m}$, i.e. $z / z_{i}=1.13$ ), in good agreement with measurements reported by Behrendt et al. (2015, 40-120 s) for the nearby site of Hambach in a different case study. Again, values of skewness within the entrainment zone and just above the CBL top are found to be large, as expected for temperature fluctuations strongly deviating from a normal distribution.

Values of kurtosis in the upper portion of the CBL (in the height interval $1160-1280 \mathrm{~m}$ ) are in the range 2.76-3.83, with a mean value of 3.36 , for water vapour mixing ratio fluctuations, while they are in the range $2.68-3.45$, with a mean value of 3.17 , for temperature fluctuations. These values indicate normally distributed (mesokurtic-Gaussian distribution) humidity and temperature fluctuations in the upper portion 

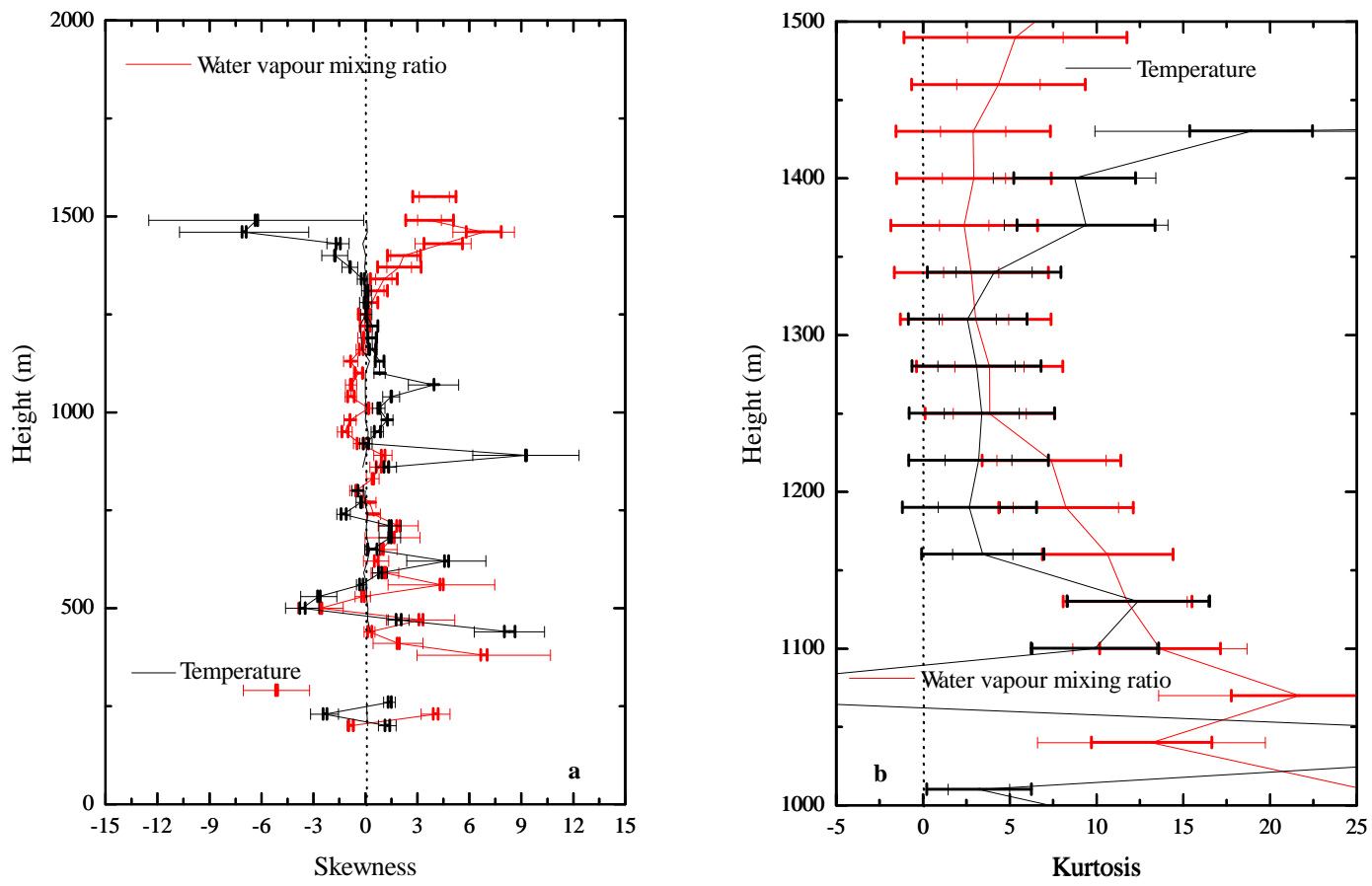

Figure 13. Vertical profiles of skewness (a) and kurtosis (b) for water vapour mixing ratio and temperature computed for the same time interval considered in Fig. 4. In the figure the thick error bars represent the noise error, while the thin error bars represent the sampling error.

of the CBL (Wulfmeyer et al., 2010; Turner et al., 2014a; Behrendt et al., 2015; Muppa et al., 2016). In the entrainment zone and above the CBL top, values of water vapour mixing ratio and temperature kurtosis are found to be large (up to 18) as a result of the presence of humidity and temperature fluctuations which strongly deviate from a normal distribution.

\section{Summary}

This paper illustrates measurements performed by the Raman lidar system BASIL during a recent field deployment which demonstrates the capability of this remote sensor to characterise turbulent processes within the CBL. For the first time simultaneous and co-located daytime measurements of the vertical profiles of higher-order moments of the turbulent fluctuations of water vapour and temperature carried out by a single instrument are reported. Thus, this paper demonstrates that state-of-the-art lidar systems, with both rotational and vibrational Raman measurement capability, allow for simultaneously determining higher-order moments (as well as skewness and kurtosis) of the fluctuations of these two fundamental turbulent variables. Results are based on the application of the autocovariance analysis introduced by Lenschow et al. (2000) to high-resolution water vapour mixing ratio $(10 \mathrm{~s}, 90 \mathrm{~m})$ and temperature $(10 \mathrm{~s}, 30 \mathrm{~m})$ time series.

Measurements of water vapour turbulent fluctuations throughout the CBL by vibrational Raman lidar, with esti- mates of up to the fourth-order moment, had been shown to be possible by Wulfmeyer et al. (2010) based on the use of the data from the Atmospheric Radiation Measurement (ARM) Raman lidar operated at the Southern Great Plains Climate Research Facility site in Oklahoma (USA). The same was demonstrated by Behrendt et al. (2015) for temperature turbulent fluctuations with rotational Raman lidar. To the best of our knowledge, BASIL is the first Raman lidar system to demonstrate the capability to simultaneously measure profiles of water vapour and temperature turbulent fluctuations up to the fourth order during the daytime throughout the atmospheric CBL.

In the present paper a comprehensive assessment of the performances of the Raman lidar system BASIL has been also carried out. Noise error profiles have been estimated based on the application of the autocovariance method and compared with the noise profiles estimated through Poisson statistics. The measurements of the higher-order moments of water vapour mixing ratio and temperature fluctuations are characterised by very small sampling and noise errors, which makes the quality of the present turbulence measurements very high and demonstrates their capability to accurately observe the structures present in the turbulent variables' profiles. In the determination of the temperature profiles, particular care was dedicated to minimising the potential systematic error associated with elastic signal crosstalk into the rotational Raman signals. For this purpose, a specific algorithm was illustrated and tested which allowed for identifying 
and removing signal leakages and for assessing the residual systematic uncertainty affecting temperature measurements after correction. In order to overcome the systematic uncertainty associated with this correction, a future upgrade of BASIL is planned with the introduction of a new Lo-J filter with high blocking at $354.7 \mathrm{~nm}$ and high central wavelength transmission to be developed benefiting from the recent advances in multi-cavity interference filter technology.

Limited data are presently available in literature in terms of measurements or model simulations of higher-order moments for both water vapour mixing ratio and temperature fluctuations. Consequently, a deeper insight into possible interpretations of their vertical variability lacks additional supporting data. The availability of state-of-the-art rotational and vibrational Raman lidar systems capable of providing high-resolution and accurate water vapour and temperature measurements will certainly help to fill this gap, at least for the measurements.

Future evolutions of this research work include the possibility of (i) comparing - for a large variety of clear-sky cases collected the during HOPE field campaign - the measurements of higher-order moments of moisture and temperature fluctuations performed by BASIL with those simultaneously measured by the University of Hohenheim water vapour DIAL and temperature rotational Raman lidar (located approx. $4 \mathrm{~km} \mathrm{E-SE),} \mathrm{(ii)} \mathrm{extending} \mathrm{the} \mathrm{analysis} \mathrm{to} \mathrm{cloud-topped}$ CBLs from different field deployments, as in fact important effect of clouds on turbulent exchange processes in the entrainment zone are expected to be relevant, (iii) comparing the measurements of higher-order moments of moisture and temperature fluctuations from BASIL with estimates from large eddy simulation, and (iv) complementing these studies with a dedicated evaluation of the correlation between temperature and moisture.

As a final remark, we need to specify that we foresee the possibility of applying this approach to characterise the diurnal evolution of turbulent processes within the convective boundary layer, by monitoring the changing patterns of water vapour and temperature higher-order moments during its different evolution phases, including day-to-night and nightto-day transitions, possibly with increased temporal resolution. However, measurements of turbulent processes with increased temporal resolution obtained by reducing the time window for the application of the autocovariance approach to $1 \mathrm{~h}$ or less would lead to an increase of the sampling error. This can be overcome by the analysis of continuous measurements such as those carried out at observatories like the ARM Southern Great Plains (SGP) site in Oklahoma (USA), the DWD Meteorologisches Observatorium in Lindenberg (Germany) and the Meteo-Swiss Centre for Meteorological Measurement Technology in Payerne (Switzerland). Furthermore, more data will become available via new field campaigns. An example of a pioneering campaign applying these techniques is the forthcoming Land-Atmosphere Feedback Experiment (LAFE, Wulfmeyer and Turner, 2016) to be held at the SGP site (see www.arm.gov/publications/ programdocs/doe-sc-arm-16-038.pdf). Finally, in order to apply the autocovariance approach to characterise the diurnal evolution of turbulent processes in clear-sky conditions, as well as in more complex meteorological situations, i.e in the presence of large-scale advection, synoptic processes and cloud-topped convective boundary layer, modifications to the detrending approach considered in the present paper are required.

\section{Data availability}

The data used in this study, together with the related metadata, are available from the public data repository $\operatorname{HD}(\mathrm{CP}) 2$ Data Archive (Stamnas et al., 2016), which is freely accessible by all users from the $\mathrm{HD}(\mathrm{CP}) 2$ Web Portal (http: //icdc.zmaw.de/1/projekte/hdcp2.html). The details for the data structure and organization can also be found in Stamnas et al. (2016).

Acknowledgement. Measurements illustrated in this paper were supported on the basis of a specific cooperation agreement between Scuola di Ingegneria - Università degli Studi della Basilicata, Leibniz Institute for Tropospheric Research and Max Planck Institute. We also wish to thank Dario Stelitano, from Scuola di Ingegneria - Università degli Studi della Basilicata, and Eva Hammann, from the Institut für Physik und Meteorologie, Universität Hohenheim, for their support in the collection and analysis of the present data set.

Edited by: H. Russchenberg

Reviewed by: two anonymous referees

\section{References}

Behrendt, A.: Temperature Measurements with Lidar, in: Lidar: Range-Resolved Optical Remote Sensing of the Atmosphere, edited by: Weitkamp, C., Springer Series in Optical Sciences, ISBN:0-387-40075-3, Springer, New York, 102, 273-305, doi:10.1007/0-387-25101-4_10, 2005.

Behrendt, A. and Reichardt, J.: Atmospheric temperature profiling in the presence of clouds with a pure rotational Raman lidar by use of an interference-filter-based polychromator, Appl. Opt., 39, 1372-1378, doi:10.1364/AO.39.001372, 2000.

Behrendt, A., Nakamura, T., Onishi, M., Baumgart, R., and Tsuda, T.: Combined Raman lidar for the measurement of atmospheric temperature, water vapor, particle extinction coefficient, and particle backscatter coefficient, Appl. Opt., 41, 7657-7666, doi:10.1364/AO.41.007657, 2002.

Behrendt, A., Pal, S., Aoshima, F., Bender, M., Blyth, A., Corsmeier, U., Cuesta, J., Dick, G., Dorninger, M., Flamant, C., Di Girolamo, P., Gorgar, T., Huang, Y., Kalthoff, N., Khodayar, S., Mannstein, H., Träumner, K., Wieser, A., and Wulfmeyer, V.: Observations of convection initiation processes with a suite of 
state-of-the-art research instruments during COPS IOP8b, Q. J. Roy. Meteor. Soc., 137, 81-100, doi:10.1002/qj.758, 2011.

Behrendt, A., Wulfmeyer, V., Hammann, E., Muppa, S. K., and Pal, S.: Profiles of second- to fourth-order moments of turbulent temperature fluctuations in the convective boundary layer: first measurements with rotational Raman lidar, Atmos. Chem. Phys., 15, 5485-5500, doi:10.5194/acp-15-5485-2015, 2015.

Bengtsson, L., Hodges, K. I., and Hagemann, S.: Sensitivity of the ERA40 reanalysis to the observing system: determination of the global atmospheric circulation from reduced observations, Tellus A, 56, 456-471, doi:10.1111/j.1600-0870.2004.00079.x, 2004.

Berg, L. K. and Stull, R. B.: A simple parameterization coupling the convective daytime boundary layer and fair-weather cumuli, J. Atmos. Sci., 62, 1976-1988, doi:10.1175/JAS3437.1, 2005.

Bhawar, R., Di Girolamo, P., Summa, D., Flamant, C., Althausen, D., Behrendt, A., Kiemle, C., Bosser, P., Cacciani, M., Champollion, C., Di Iorio, T., Engelmann, R., Herold, C., Pal, S., Riede, A., Wirth, M., and Wulfmeyer, V.: The Water vapour intercomparison effort in the framework of the convective and orographically-induced precipitation study: air-borne-togroundbased and airborne-to-airborne lidar systems, COPS Special Issue, Q. J. Roy. Meteor. Soc., 137, 325-348, doi:10.1002/qj.697, 2011.

Couvreux, F., Guichard, F., Redelsperger, J.-L., Kiemle, C., Masson, V., Lafore, J.-P., and Flamant, C.: Water-vapour velocity within a convective boundary layer assessed by large-eddy simulations and IHOP_2002 observations. Q. J. Roy. Meteor. Soc., 131, 2665-2693, doi:10.1256/qj.04.167, 2005.

Couvreux, F., Guichard, F., Masson, V., and Redelsperger, J.L.: Negative water-vapour skewness and dry tongues in the convective boundary layer: observations and large-eddy simulation budget analysis, Bound.-Lay. Meteorol., 123, 269-294, doi:10.1007/s10546-006-9140-y, 2007.

Dierer, S., Arpagaus, M., Seifert, A., Avgoustoglou, E., Dumitrache, R., Grazzini, F., Mercogliano, P., Milelli, M., and Starosta, K.: Deficiencies in quantitative precipitation forecasts: sensitivity studies using the COSMO model, Meteorol. Z., 18, 631-645, doi:10.1127/0941-2948/2009/0420, 2009.

Di Girolamo, P., Gagliardi, R. V., Pappalardo, G., Spinelli, N., Velotta, R., and Berardi, V.: Two wavelength Lidar analysis of stratospheric aerosol size distribution, J. Aerosol Sci., 26, 989-1001, ISSN:0021-8502, doi:10.1016/0021-8502(95)000258, 1995.

Di Girolamo, P., Ambrico, P. F., Amodeo, A., Boselli, A., Pappalardo, G., and Spinelli, N.: Aerosol observations by Lidar in the Nocturnal Boundary Layer, App. Opt., 38, 4585-4595, , doi:10.1364/AO.38.004585, 1999.

Di Girolamo, P., Marchese, R., Whiteman, D. N., and Demoz B. B.: Rotational Raman Lidar measurements of atmospheric temperature in the UV, Geophys. Res. Lett., 31, L01106, doi:10.1029/2003GL018342, 2004.

Di Girolamo, P., Behrendt, A., and Wulfmeyer, V.: Spaceborne profiling of atmospheric temperature and particle extinction with pure rotational Raman Lidar and of relative humidity in combination with differential absorption Lidar: performance simulations. Appl. Opt., 45, 2474-2494, doi:10.1364/AO.45.002474, 2006.

Di Girolamo, P., Behrendt, A., Kiemle, C., Wulfmeyer, V., Bauer, H., Summa, D., Dornbrack, A., and Ehret, G.: Simulation of satellite water vapour lidar measurements: Performance assess- ment under real atmospheric conditions, Remote Sens. Environ., 112, 1552-1568, doi:10.1016/j.rse.2007.08.008, 2008.

Di Girolamo, P., Summa, D., and Ferretti, R.: Multiparameter Raman Lidar Measurements for the Characterization of a Dry Stratospheric Intrusion Event, J. Atmos. Ocean. Technol., 26, 1742-1762, doi:10.1175/2009JTECHA1253.1, 2009a.

Di Girolamo, P., Summa, D., Lin, R.-F., Maestri, T., Rizzi, R., and Masiello, G.: UV Raman lidar measurements of relative humidity for the characterization of cirrus cloud microphysical properties, Atmos. Chem. Phys., 9, 8799-8811, doi:10.5194/acp-98799-2009, 2009b.

Di Girolamo, P., Summa, D., Bhawar, R., Di Iorio, T., Cacciani, M., Veselovskii, I., Dubovik, O., and Kolgotin, A.: Raman lidar observations of a Saharan dust outbreak event: Characterization of the dust optical properties and determination of particle size and microphysical parameters, Atmos. Environ., 50, 66-78, doi:10.1016/j.atmosenv.2011.12.061, 2012a.

Di Girolamo, P., Summa, D., Cacciani, M., Norton, E. G., Peters, G., and Dufournet, Y.: Lidar and radar measurements of the melting layer: observations of dark and bright band phenomena, Atmos. Chem. Phys., 12, 4143-4157, doi:10.5194/acp-12-41432012, 2012b.

Di Girolamo, P., Flamant, C., Cacciani, M., Richard, E., Ducrocq, V., Summa, D., Stelitano, D., Fourrié, N., and Saïd, F.: Observation of low-level wind reversals in the Gulf of Lion area and their impact on the water vapour variability, Q. J. Roy. Meteor. Soc., 142, 153-172, doi:10.1002/qj.2767, 2016a.

Di Girolamo, P., Cacciani, D., Scoccione, A., Summa, D., Turner, D. D., Wulfmeyer, V., Schween, J. H., and Crewell, S.: Deployment of the of the Raman lidar system BASIL in the frame of the $\mathrm{HD}(\mathrm{CP}) 2$ Observational Prototype Experiment - HOPE: upgrades of the instrument to fulfil the aims of the experiment and overview of the performed measurements, Atmos. Chem. Phys, in preparation, 2016b.

Eberhard, W. L., Cupp, R. E., and Healy, K. R.: Doppler lidar measurement of profiles of turbulence and momentum flux, J. Atmos. Ocean. Tech., 6, 809-819, 1989.

Frehlich, R. and Cornman, L.: Estimating spatial velocity statistics with coherent Doppler lidar, J. Atmos. Ocean. Tech., 19, 355366, 2002.

Garratt, J. R.: The Atmospheric Boundary Layer, Cambridge Atmospheric and Space Science Series, 336 pp., ISBN:9780521467452, 1992.

Griaznov, V., Veselovskii, I., Di Girolamo, P., Korenskii, M., and Summa, D.: Spatial distribution of doubly scattered polarized laser radiation in the focal plane of a lidar receiver, Appl. Opt., 46, 6821-6830, doi:10.1364/AO.46.006821, 2007.

Gustafson Jr., W. I. and Berg, L. K.: Implementation of the probabilistic CuP cumulus parameterization in WRF, in: 8th annual WRF user's workshop, Boulder, USA, 11-15 June, 2007.

Haeffelin, M., Angelini, F., Morille, Y., Martucci, G., Frey, S., Gobbi, G. P., Lolli S., O’DowdL C. D., Sauvage, L., XuerefRémy, I., Wastine, B., and Feist, D. G.: Evaluation of MixingHeight Retrievals from Automatic Profiling Lidars and Ceilometers in View of Future Integrated Networks in Europe, Bound.Lay. Meteorol., 143, 49-75, doi:10.1007/s10546-011-9643-z, 2012. 
Hammann, E. and Behrendt, A.: Parametrization of optimum filter passbands for rotational Raman temperature measurements, Opt. Express, 23, 30767-30782, doi:10.1364/OE.23.030767, 2015.

Hammann, E., Behrendt, A., Le Mounier, F., and Wulfmeyer, V.: Temperature profiling of the atmospheric boundary layer with rotational Raman lidar during the $\mathrm{HD}(\mathrm{CP}) 2$ Observational Prototype Experiment, Atmos. Chem. Phys., 15, 2867-2881, doi:10.5194/acp-15-2867-2015, 2015a.

Hammann, E., Behrendt, A., and Wulfmeyer, V.: Recent upgrades of the rotational Raman lidar of the University of Hohenheim for the measurement of temperature profiles in the surface layer. Reviewed extended abstracts of the 27th International Laser Radar Conference (ILRC27), New York City, USA, 249, 5-10 July, 2015b.

Kalthoff, N., Kohler, M., Barthlott, C., Adler, B., Mobbs, S. D., Corsmeier, U., Träumner, K., Foken, T., Eigenmann, R., Krauss, L., Khodayar, S., and Di Girolamo, P.: The dependence of convection-related parameters on surface and boundary-layer conditions over complex terrain, Q. J. Roy. Meteor. Soc., 137, 70-80, doi:10.1002/qj.686, 2011.

Kiemle, C., Ehret, G., Giez, A., Davis, K. J., Lenschow, D. H., and Oncley, S. P.: Estimation of boundary layer humidity fluxes and statistics from airborne DIAL, J. Geophys. Res., 102, 189-204, doi:10.1029/97JD01112, 1997.

Kiemle, C., Brewer, W. A., Ehret, G., Hardesty, R. M., Fix A., Senff, C.,Wirth, M., Poberaj G., and LeMone, M. A.: Latent heat flux profiles from collocated airborne water vapour and wind lidars during IHOP_2002, J. Atmos. Ocean. Technol., 24, 627-639, doi:10.1175/JTECH1997.1, 2007.

Lenschow, D. H. and Kristensen, L.: Uncorrelated noise in turbulence measurements, J. Atmos. Ocean. Technol., 12, 68-81, 1985.

Lenschow, D. H., Wulfmeyer., V., and Senff, C., Measuring second-through fourth-order moments in noisy data, J. Atmos. Ocean. Technol., 17, 1330-1347, doi:10.1175/15200426(2000)017<1330:MSTFOM>2.0.CO;2, 2000.

Mahrt, L.: Boundary-layer moisture regimes, Q. J. Roy. Meteorol. Soc. 117, 151-176, doi:10.1002/qj.49711749708, 1991.

McNicholas, C. and Turner, D. D.: Characterizing the convective boundary layer turbulence with a High Spectral Resolution Lidar, J. Geophys. Res.-Atmos., 119, 12910-12927, doi:10.1002/2014JD021867, 2014.

Milroy, C., Martucci, G., Lolli, S., Loaec, S., Sauvage, L., Xueref-Remy, I., Lavrič, J. V., Ciais, P., Feist, D. G., Biavati, G., and O'Dowd1, C. D.: An Assessment of PseudoOperational Ground-Based Light Detection and Ranging Sensors to Determine the Boundary-Layer Structure in the Coastal Atmosphere, Advances in Meteorology, 2012, 18 pp., doi:10.1155/2012/929080, 2012.

Milovac, J., Warrach-Sagi, K., Behrendt, A., Späth, F., Ingwersen, J., and Wulfmeyer, V.: Investigation of PBL schemes combining the WRF model simulations with scanning water vapour differential absorption lidar measurements, J. Geophys. Res.-Atmos, 121, 624-649, doi:10.1002/2015JD023927, 2016.

Muppa, S. K., Behrendt, A., Späth, F., Wulfmeyer, V., Metzendorf, S., and Riede, A.: Turbulent humidity fluctuations in the convective boundary layer: Case studies using water vapour differential absorption lidar measurements, Bound.-Lay. Meterorol., 58, 4366, doi:10.1007/s10546-015-0078-9, 2016.
Newsom, R. K, Turner, D. D., Mielke, B., Clayton, M., Ferrare, R., and Sivaraman, C.: The use of simultaneous analog and photon counting detection for Raman lidar, Appl. Opt., 48, 3903-3914, doi:10.1364/AO.48.003903, 2009.

Nocera, R.: Raman lidar measurements of the atmospheric temperature vertical profile, Master Thesis, Potenza, 2016.

Pal, S., Behrendt, A., and Wulfmeyer, V.: Elastic-backscatter lidar based characteri-zation of the convective boundary layer and investigation of related statistics, Ann. Geophys. 28, 825-847, DOI:10.5194/angeo-28-825-2010, 2010.

Radlach, M., Behrendt, A., and Wulfmeyer, V.: Scanning rotational Raman lidar at $355 \mathrm{~nm}$ for the measurement of tropospheric temperature fields, Atmos. Chem. Phys., 8, 159-169, doi:10.5194/acp-8-159-2008, 2008.

Senff, C., Bösenberg, J., Peters, G., and Schaberl, T.: Remote sensing of turbulent ozone fluxes and the ozone budget in the convective boundary layer with DIAL and radar-RASS: a case study, Contrib. Atmos. Phys., 69, 161-176, 1996.

Sorbjan, Z.: Effects caused by varying the strength of the capping inversion based on a large eddy simulation model of the shearfree convective boundary layer, J. Atmos. Sci., 53, 2015-2024, 1996.

Späth, F., Behrendt, A., Muppa, S. K., Metzendorf, S., Riede, A., and Wulfmeyer, V.: 3-D water vapor field in the atmospheric boundary layer observed with scanning differential absorption lidar, Atmos. Meas. Tech., 9, 1701-1720, doi:10.5194/amt-91701-2016, 2016.

Stamnas, E., Lammert, A., Winkelmann, V., and Lang, U.: The HD(CP)2 Data Archive for Atmospheric Measurement Data, ISPRS Int. J. Geo-Inf., 5, 124 pp., available at: http://www.mdpi. com/2220-9964/5/7/124, 2016.

Stull, R. B.: An Introduction to Boundary Layer Meteorology, Atmospheric Sciences Library, 1988.

Su, J., McCormick, M. P.,Wu, Y., Lee III, R. B., Lei, L., Liu, Z., and Leavor, K. R.: Cloud temperature measurement using rotational Raman lidar, J. Quant. Spectrosc. Ra., 125, 45-50, 2013.

Sullivan P. P., Moeng C.-H., Stevens B., Lenschow D. H., and Mayor S. D.: Structure of the entrainment zone capping the convective atmospheric boundary layer, J. Atmos. Sci., 55, 30423064, 1998.

Summa, D., Di Girolamo, P., Stelitano, D., and Cacciani, M.: Characterization of the planetary boundary layer height and structure by Raman lidar: comparison of different approaches, Atmos. Meas. Tech., 6, 3515-3525, doi:10.5194/amt-6-3515-2013, 2013.

Turner, D. D., Wulfmeyer, V., Berg, L. K., and Schween, J. H.: Water vapor turbulence profiles in stationary continental convective mixed layers, J. Geophys. Res. 119, 11151-11165, DOI:10.1002/2014JD022202, 2014a.

Turner, D. D., Ferrare, R. A., Wulfmeyer, V., and Scarino, A. J.: Aircraft evaluation of ground-based Raman lidar water vapor turbulence profiles in convective mixed layers, J. Atmos. Ocean. Technol., 31, 1078-1088, doi:10.1175/JTECH-D-13-00075-1, 2014b.

Wagner, G., Wulfmeyer, V., Späth, F., Behrendt, A., and Schiller, M.: Performance and specifications of a pulsed high-power single-frequency Ti:Sapphire laser for water-vapor differential absorption lidar, Appl. Opt., 52, 2454-2469, doi:10.1364/AO.52.002454, 2013. 
Whiteman, D. N.: Examination of the traditional Raman lidar technique, I. Evaluating the temperature-dependent lidar equations, Appl. Opt., 42, 2571-2592, doi:10.1364/AO.42.002571, 2003.

Wulfmeyer, V.: Investigation of turbulent processes in the lower troposphere with water-vapour DIAL and radar-RASS, J. Atmos. Sci., 56, 1055-1076, 1999a.

Wulfmeyer, V.: Investigations of humidity skewness and variance profiles in the convective boundary layer and comparison of the latter with large eddy simulation results, J. Atmos. Sci., 56, 1077-1087, 1999b.

Wulfmeyer, W. and Turner, D. D.: Land-Atmosphere Feedback Experiment (LAFE) Science Plan, DOE/SC-ARM-16-038, www. arm.gov/publications/programdocs/doe-sc-arm-16-038.pdf, last access: 1 July 2016.

Wulfmeyer, V.,, Behrendt, A., Bauer, H.-S., Kottmeier, C., Corsmeier, U., Blyth, A., Craig, G., Schumann, U., Hagen, M., Crewell, S., Di Girolamo, P., Flamant, C., Miller, M., Montani, A., Mobbs, S., Richard, E., Rotach, M. W., Arpagaus, M., Russchenberg, H., Schlüssel, P., König, M., Gärtner, V., Steinacker, R., Dorninger, M., Turner, D. D., Weckwerth, T., Andreas Hense, A., and Simmer, C.: Research Campaign: the Convective and Orographically induced Precipitation Study - A Research and Development Project of the World Weather Research Program for Improving Quantitative Precipitation Forecasting in Low-Mountain Regions, B. Am. Meteorol. Soc., 89, 1477-1486, doi:10.1175/2008BAMS2367.1, 2008.
Wulfmeyer, V., Turner, D. D., Pal, S., and Wagner, E.: Can water vapour Raman lidar resolve profiles of turbulent variables in the convective boundary layer?, Bound.-Lay. Meteorol., 136, 253284, doi:10.1007/s10546-010-9494-z, 2010

Wulfmeyer, V., Hardesty, M., Turner, D. D., Behrendt, A., Cadeddu, M., Di Girolamo, P., Schlüssel, P., van Baelen, J., and Zus, F.: A review of the remote sensing of lower-tropospheric thermodynamic profiles and its indispensable role for the understanding and the simulation of water and energy cycles, Rev. Geophys., 53, 819-895, doi:10.1002/2014RG000476, 2015.

Wulfmeyer, V., Muppa, S., Behrendt, A., Hammann, E., Späth, F., Sorbjan, Z., Turner, D. D., and Hardesty, R. M.: Determination of convective boundary layer entrainment fluxes, dissipation rates, and the molecular destruction of variances: Theoretical description and a strategy for its confirmation with a novel lidar system synergy, J. Atmos. Sci., 73, 667-692, doi:10.1175/JAS-D14-0392.1, 2016. 